\title{
Integration of Multitargeted Polymer-Based Contrast Agents with Photoacoustic Computed Tomography: An Imaging Technique to Visualize Breast Cancer Intratumor Heterogeneity
}

\author{
Lei $\mathrm{Li}^{\dagger}$, Deepanjali Patil ${ }^{\ddagger}$, Greg Petruncio ${ }^{\ddagger}$, Kathleen K. Harnden\#, Jisha V. Somasekharan§, \\ Mikell Paige $^{\ddagger}$, Lihong V. Wang ${ }^{\dagger}$, Carolina Salvador-Morales ${ }^{\ddagger},{ }^{*}$ \\ ${ }^{\dagger}$ Caltech Optical Imaging Laboratory, Andrew and Peggy Cherng Department of Medical \\ Engineering and Department of Electrical Engineering, California Institute of Technology, \\ Pasadena, CA 91125, USA \\ ¥Department of Chemistry \& Biochemistry, George Mason University, 4400 University Drive, \\ Fairfax, VA 22030, USA \\ \#Inova Schar Cancer Institute, 8081 Innovation, Park Dr, Fairfax, VA 22031 \\ §Research and Post Graduate Department of Chemistry, MES Keveeyam College, Valanchery, \\ Kerala 676552, India
}

\begin{abstract}
One of the primary challenges in breast cancer diagnosis and treatment is intratumor heterogeneity (ITH), i.e., the co-existence of different genetically and epigenetically distinct malignant cells within the same tumor. Thus, the identification of ITH is critical for designing better treatments and hence to increase patient survival rates. Herein, we report a non-invasive hybrid imaging technology that integrates multitargeted and multiplexed patchy polymeric photoacoustic contrast agents (MTMPPPCAs) with single-impulse panoramic photoacoustic computed tomography (SIPPACT). The target specificity ability of MTMPPPCAs to distinguish Estrogen and Progesterone receptors-positive in breast tumors was demonstrated through both fluorescence and photoacoustic measurements and validated by tissue pathology analysis. This work provides the proof-of-concept of the MTMPPPCAs/SIP-PACT system to identify ITH in non-metastatic tumors, with both high molecular specificity and real-time detection capability.
\end{abstract}

*Corresponding author: csalvado@gmu.edu.

Author Contributions

C.S.M. conceived the research idea and designed research; C.S.M, L.L., D.P., performed research; C.S.M., L.L., D.P., analyzed data; C.S.M., L.L., D.P., L.W., wrote the paper; G.P., M.P. partially developed the organic synthesis of the $\mathrm{NH}_{2}$-PEG-Estrone; J.S., synthesized the squaraine (SQ650) dye; K.H. provided clinical inputs.

Supporting Information. The Supporting Information is available free of charge online at Additional experimental data including calculations for In vitro cytotoxicity assessment of MTMPPPCAs (Equation 1), Encapsulation efficiency (EE) of Squaraine (SQ650) and ICG (Equation 2), Zeta potential measurements (Figure S1), NP size stability studies (Figure S2), and Pathology studies (Figure S3-S5). (PDF)

In compliance with the George Mason University guidelines, C.S.M discloses her financial interest in Nano-Guided Technologies, a biopharmaceutical developing nanoparticle technologies for medical applications. Nano-Guided Technologies did not support the aforementioned research, and this company has no rights to any technology or intellectual property developed as part of this research. L.V. Wang has a financial interest in Microphotoacoustics, Inc., CalPACT, LLC, and Union Photoacoustic Technologies, Ltd., which, however, did not support this work. The other authors declare no competing financial interests. 


\section{Graphical Abstract}

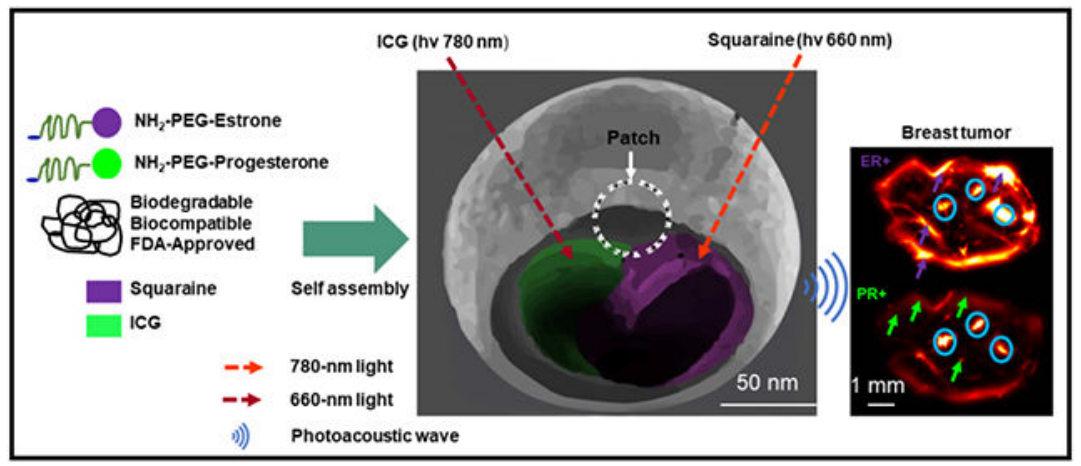

\section{Keywords}

breast cancer; intra-tumor heterogeneity; multitargeted; single-impulse panoramic photoacoustic computed tomography; patchy particles

Breast cancer accounts for the second leading cause of cancer death globally $(11.6 \%)$ with an alarming mortality rate of $6.6 \%$ as per 2018 global cancer statistics. ${ }^{1,2}$ One of the primary challenges in breast cancer diagnosis and treatment is intra-tumor heterogeneity (ITH). ITH is the co-existence of different genetically and epigenetically distinct malignant cells within the same tumor. ${ }^{3-5}$ It is responsible for $30 \%$ of cancer-related deaths worldwide in women as it is closely associated to cancer progression, resistance to therapy, and recurrences. ${ }^{6}$ The current treatment options for breast cancer are guided by critical factors, including molecular subtypes, ${ }^{7,8}$ locations, metastatic stages, previous treatments, and other parameters. ${ }^{3,4,6}$ Luminal A (LA), luminal B (LB), human epidermal growth factor receptor 2 (HER2) enriched cells, and triple negative breast cancer (TNBC) are the main subtypes treated in clinical settings. ${ }^{9}$ LA and LB are present in $70 \%$ of breast cancer tumors, ${ }^{10,11}$ whereas HER 2 and TNBC are found in $15-30 \%$ and $15 \%$ of breast cancers, respectively. 12-14 TNBC is the most aggressive subtype and has the worse prognosis than the other three. 15

Currently, positron emission tomography/computed tomography (PET/CT) is the only imaging modality that is capable of rendering ITH information based on metabolic activity, 16-19 cell proliferation and Estrogen Receptor (ER) status in breast cancer tumors. ${ }^{20-22}$

However, the main challenges of using PET/CT include the high-cost, long term exposure to radiation, and the side effects of radiotracers. Furthermore, although PET/CT can analyze different molecular subtypes of breast cancer, the exact localization of cancer cell receptors for identifying ITH requires additional confirmation from histology studies to avoid falsepositive predictions. ${ }^{23-26}$ Thus, there is an unmet critical need in oncology care for a noninvasive technology with multitargeting ability, and high molecular specificity to localize and visualize ITH at non-and-metastatic stages of breast cancer.

Photoacoustic tomography (PAT), paired with targeted contrast agents, holds a great potential to fill this clinical gap. ${ }^{27-32}$ Till now, PAT, a noninvasive and ionizing radiation-free 
technique, is the only high-resolution optical imaging modality that breaks the optical diffusion limit, which provides high spatiotemporal resolution and deep tissue penetration. 33-37 In PAT, the ultrasonic photoacoustic (PA) waves re-emitted by the tissue chromophores are subsequently detected to generate tomographic images with optical contrasts. ${ }^{35,}, 38-40 \mathrm{~A}$ recent advancement, single-impulse panoramic photoacoustic computed tomography (SIPPACT), provides all the above-mentioned functionalities with high molecular contrast. ${ }^{41}$ Since abnormally increased vasculature and hemoglobin at tumor sites produce strong intrinsic PA contrast, PAT is ideally suited for visualizing angiogenesis and subsequently determining the intratumor heterogeneity. ${ }^{42,43}$ Recently, it has been used to distinguish different molecular subtypes including LA, LB, and TNBC based on the overall tissue composition and physiological properties of breast cancer tumors. ${ }^{44-46}$ Despite these enormous advances, PAT has not yet been established in clinical settings for the diagnosis and treatment of breast cancer.

Exploiting the molecular specificity offered by targeted nanoparticles can drive the development of high throughput imaging probes for tumor visualization in real time. ${ }^{47-49}$ Previously, we have developed patchy polymeric poly (lactic-co-glycolic acid) (PLGA) nanoparticles. ${ }^{50}$ These are a class of anisotropic particles that have one or more surfaceexposed domains with different surface chemistry relative to the rest of the particle. ${ }^{50,51} \mathrm{~A}$ unique feature of MTMPPPCAs is the patchy surface that makes the targeting moieties to arrange themselves in clusters. ${ }^{52}$ The cluster effect enables the entire nanoparticles to acquire multiple homogeneous or heterogeneous functionalities that can detect different receptors simultaneously with enhanced targeting efficacy, as earlier reported. ${ }^{50-52}$

Herein, we report the development of a personalized hybrid imaging tool to visualize ITH in non-metastatic breast cancer tumors. Our results show higher MTMPPPCAs uptake in the targeted tumor than in the untargeted. Furthermore, in vivo fluorescence biodistribution studies revealed the presence of ER+ and Progesterone Receptor (PR+) in the tumor site. EX vivo PA imaging studies validated the fluorescence results. Furthermore, PA was able to differentiate the presence of both receptors in colocalized and non-colocalized areas. IHC analysis confirmed the location of ER+ and PR+ visualized by fluorescence and PA imaging.

\section{RESULTS AND DISCUSSION}

\section{Synthesis and characterization of MTMPPPCAs}

In this work, we have designed MTMPPPCAs endowed with high molecular specificity to detect LA and LB molecular subtypes. The MTMPPPCAs were synthesized following a self-assembly strategy shown in Figure 1. The PLGA shell surface was chemically modified with two unique targeting moieties, namely, $\mathrm{NH}_{2}$-PEG-Estrone and $\mathrm{NH}_{2}$-PEG-Progesterone, which bind specifically to the estrogen and progesterone receptors overexpressed in breast cancer cells. Near-infrared fluorophores such as Indocyanine green (ICG) and Squaraine 650 (SQ650) dyes formed the inner lining of the core and served as PA reporters.

The $\mathrm{NH}_{2}$-PEG-Estrone targeting moiety was synthesized by conjugating estrone ethyl glycolic acid (EGA) with the PEG-diamine molecule (Figure 2A). Derivatization of estrone was essential to construct an ideal position for conjugating the PEG-diamine molecule 
without hampering the binding affinity at the conjugation site of estrone. We modified the estrone molecule by synthesizing the estrone ester at the $\mathrm{C} 3$ position with ethyl bromo ester under basic conditions.

The further saponification reaction in the presence of sodium hydroxide resulted in the production of EGA in quantitative yields. The end group modification of PEG-diamine with EGA proceeded through regular amine-acid coupling chemistry using HATU as the coupling reagent. The conjugation of the modified estrone was demonstrated by the presence of aromatic proton signals at $6.81-7.19 \mathrm{ppm}$ in the ${ }^{1} \mathrm{H}-\mathrm{NMR}$ spectrum (Figure 2B). FTIR analysis of $\mathrm{NH}_{2}$-PEG-Estrone revealed the presence of aromatic peaks of estrone around 1500 to $1600 \mathrm{~cm}^{-1}$ (Figure 2C). The presence of carbonyl groups of estrone at C-17 position along with the amide bond of modified estrone at C-3 with PEG-amine is observed from peaks present at 1620 and $1742 \mathrm{~cm}^{-1}$ bond. TLC showed the formation of the molecule (Figure 2D). The polar carboxylic acid functionalized EGA $\left(R_{f}=0.333\right)$ differed substantially upon conversion to the non-polar $\mathrm{NH}_{2}$-PEG-Estrone $\left(\mathrm{R}_{\mathrm{f}}=0.777\right)$; confirming the successful conjugation of estrone moiety with the PEG molecule.

The second targeting moiety, $\mathrm{NH}_{2}$-PEG-Progesterone, was initiated by a synthesis of the aminooxy PEG molecule (Figure 3A). Next, the ketone group of progesterone was conjugated with the aminooxy-PEG molecule via oxime formation. The oxime bond demonstrated higher stability compared to the other amine or hydrazine functionalities at physiological conditions. The ${ }^{1} \mathrm{H}-\mathrm{NMR}$ peaks at $5.74 \mathrm{ppm}(\mathrm{s},-\mathrm{CH}), 4.15 \mathrm{ppm}\left(\mathrm{m},-\mathrm{CH}_{2}\right)$, $3.64 \mathrm{ppm}\left(\mathrm{bs},-\mathrm{CH}_{2}\right)$, and the characteristic progesterone methyl peaks $\left(-\mathrm{CH}_{3}\right)$ at $2.12 \mathrm{ppm}$, $1.12 \mathrm{ppm}$, and $0.6 \mathrm{ppm}$ were confirmed (Figure 3B). The FTIR peaks of $\mathrm{NH}_{2}$-PEGProgesterone appeared at $1642 \mathrm{~cm}^{-1}$, confirming the $-\mathrm{C}=\mathrm{N}$ (imine) bond formation and validating the successful synthesis of $\mathrm{NH}_{2}$-PEG-Progesterone (Figure 3C). The TLC analysis demonstrated complete conjugation of progesterone with the aminooxy-PEG molecule $\left(R_{f}=0.422\right)$, as no traces of starting material were visible on the spot $C$ of the reaction mixture compared to the starting material spot A (Figure 3D).

\section{Receptor specific binding affinity studies using Surface Plasmon Resonance (SPR)}

We used the SPR technique to assess the molecular specificity of $\mathrm{NH}_{2}$-PEG-Estrone and $\mathrm{NH}_{2}$-PEG-Progesterone (Figure 4). The SPR responses of the analyte (i.e., $\mathrm{NH}_{2}$-PEGEstrone) were plotted at different concentrations (Figure 4 A-C). The SPR results show that the sharp shape of the sensorgrams in the association stage of the interaction indicates the binding of $\mathrm{NH}_{2}$-PEG-Estrone to full length recombinant human estrogen alpha receptor (FLER-a) at different micromolar concentrations (Figure 4A). Fitting the sensorgram data to an appropriate kinetic binding model allowed the calculation of the kinetic disassociation $\left(\mathrm{K}_{\mathrm{D}}\right)$ rate constant. Assuming 1:1 binding affinities and fitting the dose response plot revealed that the $\mathrm{K}_{\mathrm{D}}$ value of FLER-a was $1.5 \mu \mathrm{M}$. This value indicates an excellent binding affinity between the analyte (i.e., $\mathrm{NH}_{2}$-PEG-Estrone) and the ligand (i.e., FLER-a). The fact that $\mathrm{NH}_{2}$-PEG-Estrone shows little binding or negligible binding to estrogen-related receptor beta (ERR- $\beta$ ) (Figure 4B) or HER2 (negative controls) (Figure 4C), respectively, demonstrates the preferential binding of $\mathrm{NH}_{2}$-PEG-Estrone to FLER- $\mathrm{a}$. With respect to the molecular interaction between $\mathrm{NH}_{2}$-PEG-Progesterone and the progesterone receptor (PR), 
we observed specific binding at different concentrations, as shown in Figure 4 D-F.

Following the same rationale described above, we found that the $\mathrm{K}_{\mathrm{D}}$ for progesterone was 10 $\mu \mathrm{M}$ (Figure $4 \mathrm{D}-\mathrm{F}$ ). The binding affinity response was higher for $\mathrm{NH}_{2}$-PEG-Progesterone compared to ERR- $\beta$ (Figure 4E) and FLER-a (Figure 4F) at different concentrations which suggests its molecular specificity with the progesterone receptor.

\section{Physicochemical characterization of MTMPPPCAs}

A self-assembled construct with the targeting moieties on the PLGA shell surface and the PA reporter dyes forming the inner lining of the MTMPPPCAs' core was successfully achieved. The mean diameters of MTMPPPCAs and Untargeted Multiplexed Patchy Polymeric PA Contrast Agents (UTMPPPCAs), were $169.3 \pm 5.6 \mathrm{~nm}$ and $180.1 \pm 2.4 \mathrm{~nm}$ respectively, showing a narrow size distribution (Figure 5A). The average zeta potentials of both targeted and untargeted nanoparticles were $-21.4 \pm 1.7 \mathrm{mV}$ and $-23.03 \pm 1.33 \mathrm{mV}$, correspondingly (Figure S1). Furthermore, the mean particle size of MTMPPPCAs suspended in 1X PBS did not change within 21 days, exhibiting excellent long-term size stability (Figure S2). 2D Stochastic Optical Reconstruction Microscopy (STORM) images clearly showed the patchy nature of the MTMPPPCAs' surface (Figure 5B-D). The donutlike shape confirmed the MTMPPPCAs' hollowness core structure (Figure 5B-D). The presence of $\mathrm{NH}_{2}$-PEG-Estrone-Alexa 647 and $\mathrm{NH}_{2}$-PEG-Progesterone-Cy3B is observed in both nanoparticle's surface and patch, but it is more prominent in the latter, as shown in Figures 5B and C, respectively. The single labeled experiments served as control samples for the two-color experiment. The dual STORM imaging experiment is presented in Figure 5D. In this picture, the presence of $\mathrm{NH}_{2}$-PEG-Estrone-Alexa-647/ $\mathrm{NH}_{2}$-PEG-Progesterone is indicated in white and red colors, respectively. These results suggest that the MTMPPPCA patch is formed by a heterogeneous mixture of both PEGylated targeted moieties. Additional characterization was performed by electron microscopy. TEM and SEM studies show the spherical-like shape and monodisperse characteristic of the synthesized MTMPPPCAs (Figure 5E-H). To assess the MTMPPPCAs' PA imaging performance, we conducted phantom studies and absorbance measurements. ${ }^{53}$ Figure 6A shows the PA images of nanoparticles with ICG, nanoparticles with SQ650, and MTMPPPCAs. Both PA and optical absorption spectra exhibit two peaks at $660 \mathrm{~nm}$ and $780 \mathrm{~nm}$, corresponding to the presence of SQ650 and 780 ICG, respectively (Figure 6D-E). The PA spectra of ICG and SQ650 were used for the spectral unmixing computation. The encapsulation efficiency (EE) for SQ650 and ICG was calculated as 55\% and 46\% (SI Equation 2), respectively. The encapsulation results correlate well with PLGA copolymer ratio $(75: 25)$ used during the nanoparticle synthesis.

\section{In vitro assessment of the cell uptake of MTMPPPCAs in T-47D and MDA-MB-231 breast cancer cell lines}

The MTMPPPCAs' receptor specific targeting capabilities were evaluated by incubating them with human breast cancer cell lines: 1) T-47D cells (ER+ and PR+), and 2) MDAMBA-231 (ER-, PR-, HER2-). Cell uptake was assessed via Fluorescence-Activated Cell Sorting (FACS) technique. The results in Figure 7A show significantly increased median fluorescence intensity (MFI) upon uptake by the T-47D cells (1250 a.u.) compared to MDAMB-231 cell (400 a.u.) after $24 \mathrm{~h}$ of incubation. The receptor mediated cell uptake of 
MTMPPPCAs is statistically significant ( $\mathrm{p}<0.05$ ) in the T-47D compared to the MDAMB-231 cells. Furthermore, the cell uptake results validated the specific binding of $\mathrm{NH}_{2}-$ PEG-Estrone and $\mathrm{NH}_{2}$-PEG-Progesterone with ER+ and PR+ determined with SPR (Figure 4A-F). Notably, even though the internalization of UTMPPPCAs was observed in both cell lines, the MFI was lower than the targeted counterparts, which is attributed to the passive uptake of MTMPPPCAs in the tumor cells. The site-specific internalization of MTMPPPCAs was visualized and validated by confocal microscopy (Figure 7B-C). A higher accumulation of MTMPPPCAs was observed in the cytoplasm or nucleus of the breast cancer cells than that of the UTMPPPCAs. Overall, these results demonstrate the in vitro targeting ability of MTMPPPCAs to bind specifically to T-47D breast cancer tumor cells, that overexpress ER+ and PR+.

\section{Assessment of the cellular toxicity of MTMPPPCAs}

A dose-dependent cell viability study was performed to assess the cellular toxicity of MTMPPPCAs. We evaluated the percent of T-47D cancer cell viability in the presence of the MTMPPPCAs at different concentrations and compared with that of UTMPPPCAs and targeted patchy polymeric nanoparticles (TPPNPs). TPPNPs is the control nanoparticle sample (i.e., nanoparticles functionalized with the targeting moieties but not loaded with PA reporters). As shown in Figure 8, More than 90\% of T-47D cells were still alive after being exposed to MTMPPPCAs at different concentrations for $24 \mathrm{~h}$, suggesting that MTMPPPCAs are not toxic at the cellular level.

\section{In vivo assessment of targeting efficacy of MTMPPPCAs in orthotopic cell line-derived xenograft (CDX) breast cancer model}

We further investigated the targeting efficacy of MTMPPPCAs using an orthotopic CDX breast cancer model in vivo (Figure 9). We implanted $7 \times 10^{6}$ freshly harvested human breast cancer cells (T-47D or MDA-MB-231) in the fourth abdominal mammary fat pad of six female athymic nude mice. When the tumor reached an average volume of $70 \mathrm{~mm}^{3}$, we administered $1200 \mu \mathrm{g}$ of a combination dose of MTMPPPCAs via tail-vein injection. The targeted nanoparticles (TNP) combination dose was composed of (TNP+SQ650+Estrone, TNP+SQ650+ICG+Progesterone+Estrone, and TNP+SQ650+ICG+Estrone) to differentiate ER+ from PR+ through the fluorescence and PA signals emitted by SQ650 and ICG. Realtime biodistribution studies were performed to assess the in vivo targeting efficacy of MTMPPPCAs functionalized with $\mathrm{NH}_{2}$-PEG-Estrone and $\mathrm{NH}_{2}$-PEG-Progesterone. The ER was localized and visualized by SQ650 (Figure 8 top panel), while the PR was visualized by ICG (Figure 9 bottom panel). Another group of six female mice was administered with UTMPPPCAs with a combination dose of untargeted nanoparticles (UTNP) (UTNP+ICG +SQ650, UTNP+ICG, UTNP+SQ650). In the third group, we injected a combination dose of MTMPPPCAs in MDA-MB-231 tumor-bearing mice (negative control group). The mice were imaged with the in vivo Imaging System (IVIS) at 1, 3, and $6 \mathrm{~h}$. We detected the presence of SQ650 and ICG in the MTMPPPCAs and UTMPPPCAs.

When comparing the biodistribution profile of the T-47D tumor-bearing mice with MDAMB-231 tumors based on the presence of SQ650 in the mice at the dorsal position, we observed that more nanoparticles were circulating in the bloodstream at all time points than 
that in the negative control group (Figure 9, top and bottom panels). The results were expected because the MTMPPPCAs were designed to bind specifically to cancer cells overexpressing ER and PR. MDA-MB-231 tumors do not express any of these receptors. Thus, it was expected to observe nanoparticle accumulation in the liver, spleen, kidneys, and intestines as corroborated in the ventral position of the untargeted mice in the negative control group (Figure 9, top and bottom panel, left and right sides). Also, we observed more nanoparticle uptake in the liver and spleen of the targeted mice in the negative control group than that of the targeted testing group, as shown in the biodistribution profile obtained with the ICG fluorescence signal (Figure 9, bottom panel, left and right sides).

Furthermore, in both the testing and negative control groups, medium fluorescence signals of free SQ650 were observed in the kidneys, urinary bladder, and intestines at 3 and $6 \mathrm{~h}$ time points (Figure 9, upper panel), suggesting that part of SQ650 leaks out from the polymeric matrix. Free ICG accumulated in the liver and spleen was also observed in both groups (Figure 9, bottom panel). Notably, despite the mice received a high dose of MTMPPPCAs, no signs of toxicity were observed in the animals. The in vivo biodistribution studies revealed that the ICG and SQ650 are cleared out from the mice's body primarily via the liver and urinary bladder, reinforcing the safety aspect of MTMPPPCAs. Thus, enhanced uptake was detected in MTMPPPCAs' tumor compared to that of UTMPPPCAs, highlighting the molecular specificity and the highly vascularized nature of the implanted breast tumors. The difference in the fluorescence signal emitted by SQ650 and ICG can be higher if the EE is increased by improving the polymer matrix's dye stability. Naked ICG and SQ650 leaked out from the PLGA nanoparticles in vivo testing. Hence, further improvements can be made in the next generation of MTMPPPCAs.

\section{Assessment of ex vivo targeting efficacy of MTMPPPCAs}

The in vivo biodistribution studies show that MTMPPPCAs or UTMPPPCAs tend to accumulate in tumors and off-target organs (i.e., liver, spleen, urinary bladder, and kidneys). These results were confirmed by the ex vivo biodistribution studies, which allowed us to investigate further the tumor uptake of MTMPPPCAs. The ex vivo analysis was performed immediately after 6-h post-injection. Fluorescence signals from organs such as tumors, hearts, spleens, lungs, urinary bladders, and kidneys were obtained for both targeted and untargeted T-47D tumor-bearing mice. Significant uptake of MTMPPPCAs in the T-47D tumor was observed at 6-h post-injection for SQ650, while the fluorescence intensity of ICG was moderately low (Figure 10). The uptake of untargeted particles in the T-47D tumor was lower than the targeted particles, indicating the site-specific internalization of MTMPPPCAs. The lower uptake of untargeted particles in the tumor tissue occurs due to the enhanced permeability effect (EPR) of the tumor. Notably, the corresponding ex vivo image clearly showed a pronounced tumor uptake of MTMPPPCAs in the T-47D tumor (Figure 10), confirming the molecular specificity property of the engineered contrast agents. Accumulation of NPs was observed in other organs, including liver, spleen, lungs, urinary bladder, and kidneys for both targeted and untargeted NPs, showing the regular uptake effect of the reticuloendothelial system (RES). Importantly, the administration of a combination dose comprised of single or double targeting moiety as well as PA receptors helped to locate the ER and PR in the tumor region. Thus, the ex vivo tumor uptake results demonstrated that 
the engineered MTMPPPCAs could specifically accumulate in the tumor due to the ER+ and $\mathrm{PR}+$ mediated receptor-ligand interaction, thereby yielding enhanced imaging effect of contrast agents.

\section{Visualization of ITH in tumors ex vivo}

The ER and PR receptor-specific internalization and distribution of MTMPPPCAs within the tumor sections were identified and visualized with fluorescence imaging, and validated with IHC and H\&E staining studies. The receptor-specific tissue penetration and distribution of targeted MTMPPPCAs (Figure 11 A-D) were clearly observed throughout the T-47D tissue section using the qualitative immunohistochemistry (IHC) analysis, and the untargeted counterparts were shown in Figure 11 F-I. The localization of estrogen receptor one (ESR1) and progesterone receptor (PR) receptors was evident, as shown by the brown stains in the targeted group, suggesting that MTMPPPCAs were distributed evenly between the intracellular and intercellular compartments of the tumor tissue. The results also revealed the exact localization of the ER and PR receptors in the tumoral region, which agreed with the fluorescent imaging results (Figure $10 \mathrm{~A}, \mathrm{~B}, \mathrm{~F}, \mathrm{G}$ ). The colocalization of ER and PR in the tumor site was differentiated based on the staining pattern for ESR1 and PR antigens. For the untargeted nanoparticles, lower tracer activity was observed in the tumor. The H\&E results (Figure 11 E-J) confirmed the overall morphology of tumor cells, where eosinophilic color represents the cytoplasm and dark purple represents nuclei. The tumors exhibited significant stroma (dark pink areas) with the presence of extracellular fibrous matrix, and the cells were arranged in clusters (Figure $11 \mathrm{E}$ ) and strands (Figure $11 \mathrm{~J}$ ). No cell toxicity induced by MTMPPPCAs was found with histology studies (Figure S3-S5). A higher level of ER+ and PR+ was detected in the targeted tumor than that of the untargeted tumor, matching well with the fluorescence results.

\section{Ex vivo PA Imaging}

MTMPPPCAs loaded with two PA reporters (SQ650 and ICG) were used to identify the presence of ER+ and PR+ receptors inside the breast tumor. We embedded the excised tumor in agarose gel and imaged it at two peak wavelengths. The light was illuminated from the top onto the tumor for PA excitation. During PA imaging, the tumor was placed in the center of the full-ring ultrasonic transducer array. By elevational scanning the tumor across the focal plane of the transducer array, we obtained a series of cross-sectional images of the tumor. The PA images shown in Fig. 12 are the integration projections of cross-sectional images of the tumor. Next, we performed spectral unmixing to accurately separate the photoacoustic signals of SQ650 and ICG, revealing the intratumor heterogeneity in Fig. 12A-C. Figure 12A shows the averaged PA amplitude of SQ650 and ICG inside the tumor, illustrating the presence of $\mathrm{ER}+$ and $\mathrm{PR}+$ receptors in the breast tumor. A spectral unmixed PA image of the tumor, as shown in Figure 12B, maps the distributions of ER+ and PR+. Figure 12B also revealed colocalization areas (purple circles), where both receptors are present in the same tumor site. By segmenting the colocalization areas (regions A, B, and C in Figure 12B), we found the PA signals from SQ650 in different parts of the tumor were higher than those of ICG, indicating that the tumor is predominantly ER+ (Figure 12C). 


\section{Biosafety aspect of MTMPPPCAs}

It is important to investigate the biosafety aspect of MTMPPPCAs to achieve its medical translation. The hemolytic assay shows that the highest $(12 \mathrm{mg} / \mathrm{ml})$ and lowest concentrations $(1.3 \mathrm{mg} / \mathrm{ml})$ of MTMPPPCAs induced $4.1 \%$ and $2.1 \%$ of hemolysis, respectively (Figure 13). Thus, at these concentrations, MTMPPPCAs are slightly hemolytic and may not be compatible with blood. However, pathology studies of the targeted, untargeted, and control group (i.e., no MTMPPPCAs administration) showed the absence of macrophages and necrotic tissue, which indicate no tissue toxicity (Figure 14). Furthermore, the cell viability assay does not show levels of toxicity either. Overall, these results suggest that MTMPPPCAs are not toxic at the cellular and tissue levels but not blood compatible at those concentrations.

\section{CONCLUSION}

Our synthesized MTMPPPCAs showed excellent receptor-specific targeting efficiency in the $\mathrm{ER}+$ and $\mathrm{PR}+$ breast tumors with rapid internalization and accumulation and significant particle clearance profile. The in vitro, in vivo fluorescence, and ex vivo PA studies corroborated with the IHC analysis, demonstrated the feasibility of the MTMPPPCAs/SIPPACT imaging technology to simultaneously visualize breast cancer biomarkers of different molecular subtypes with high molecular specificity. Furthermore, the toxicity assessment suggests that MTMPPPCAs are not toxic at the cellular and tissue levels, but may not be blood compatible at specific concentrations. The optimization of MTMPPPCAs will be required to achieve its usage in clinical settings. The outlook will include the synthesis of two additional targeting moieties: HER2 and Trophoblast Cell-Surface Antigen 2 (Trop-2) to detect HER2-enriched cells and TNBC. This addition will require more contrast agents. Near-infrared-II probes provide diverse candidates for the contrast agent selection.

The development of multitargeting and multiplexed contrast agents that simultaneously can detect LA, LB, HER2 enriched cells, and TNBC at the metastatic stage can make a difference in the oncology field. At this stage cancer patients need regular scans and frequent adjustment treatments that cannot be carried out with existing techniques. The

MTMPPPCAs/SIP-PACT technology has the potential to address this clinical gap, as well.

\section{MATERIALS AND METHODS}

\section{Materials}

Estrone, progesterone, polyethylene glycol (PEG, 3,400 Da), polyvinyl alcohol (9,000-10,000 Da), Amicon® Ultra Centrifugal Filters with MWCO 10,000 were purchased from Sigma Aldrich, USA. All reagents and solvents were of analytical/HPLC grade and used as received. ICG dye was purchased from AdooQ Bioscience, USA. Squaraine 650 (SQ650) dye was synthesized using the reported method. ${ }^{54}$ PLGA (75:25) was purchased from Lactel Absorbable Polymers, USA. Dialysis membranes (MWCO 3500) used for purification of modified PEG ligands were purchased from Spectra Por-3, USA. Receptors required for SPR binding affinity analysis such as the recombinant protein of human progesterone receptor (PGR) was purchased from Origene, USA; full-length ER alpha 
recombinant protein receptor, Gibco ${ }^{\mathrm{TM}}$ human recombinant insulin, Gibco ${ }^{\mathrm{TM}}$ fetal bovine serum, Trypsin-EDTA (0.25\%) phenol red, enzyme-free sterile phosphate buffered saline (PBS), Invitrogen cell tracker ${ }^{\mathrm{TM}}$ red CMTPX dye were obtained from Thermo Fisher Scientific, USA. The T-47D cells, MDA-MB-231 cells, RPMI-1640 medium, Leibovitz's L-15 medium, and sterile DMSO were purchased from American Type Culture Collection (ATCC), USA. Zombie Violet ${ }^{\mathrm{TM}}$ fixable viability kit was obtained from Biolegend, USA. CytoTox-Fluor ${ }^{\mathrm{TM}}$ Cytotoxicity Assay kit was purchased from Promega, USA. High concentration (HC) and LDEV-free matrigel for tumor implantation were purchased from Corning Life Sciences, USA.

The proton nuclear magnetic resonance $\left({ }^{1} \mathrm{H}-\mathrm{NMR}\right)$ experiments ( $\delta$ scale) were carried out on Jeol JNM-ECP Series Fourier Transform Nuclear Magnetic Resonance (FT-NMR) system at a magnetic field strength of $9.4 \mathrm{~T}$, operating at $400 \mathrm{MHz}$. The ${ }^{1} \mathrm{H}-\mathrm{NMR}$ spectra were recorded in $\mathrm{CDCl}_{3}, \mathrm{D}_{2} \mathrm{O}$, and DMSO-d6, respectively. Fourier Transform Infrared (FTIR) spectroscopy characterization was performed using a Jasco FTIR 4100 spectrophotometer with a wavelength scanning range of $500-4000 \mathrm{~cm}^{-1}$. The spectra were recorded using the optimum spectrometer parameters employing 36 scans per sample and a resolution of $4 \mathrm{~cm}^{-1}$. Surface Plasmon Resonance (SPR) studies were performed using a Biacore T200 instrument with a CM5 chip at $25^{\circ} \mathrm{C}$. The nanoparticle size determination was performed using Zetasizer Nano ZS from Malvern at $25^{\circ} \mathrm{C}$. The spectrum analysis was performed using the Agilent Cary $60 \mathrm{UV}$-Vis Spectrophotometer. Fluorescence measurements were carried out on a Shimadzu RF-6000 spectrofluorometer. TEM images were recorded using FEI Talos TEM, operating at $80 \mathrm{kV}$ accelerating voltage. The SEM images of nanoparticles were recorded using a Zeiss Ultra 60 Field Emission Scanning Electron Microscope. All animal experiments were carried out according to the guidelines of the Animal Ethics Committee of the George Mason University (GMU). Athymic nude female mice (4-6 weeks old; 20-30 g body weight) were purchased from Jackson Laboratory and maintained at the Biomedical Research Laboratory (BRL), GMU (USA). Cultured fresh breast cancer cells were harvested and suspended in a solution of 50\% matrigel and 50\% 1X PBS for tumor implantation. About $7 \times 10^{6}$ cells/ $100 \mu \mathrm{L}$ were injected subcutaneously near the fourth mammary gland in the abdominal cavity of the mice. The in vivo biodistribution studies were performed once the tumor volume reached $\sim 70$ $\mathrm{mm}^{3}$.

\section{Synthesis of $\mathrm{NH}_{2}$-PEG-Estrone}

PEGylated estrone targeting moiety was synthesized via a stepwise route (Figure 2A). Initially, estrone was modified into its glycolic acid derivative for functionalization with PEG polymer (Figure 2A, Step I). Estrone (100 mg, $0.37 \mathrm{mmol}$ ) was dissolved in $2 \mathrm{~mL}$ of tetrahydrofuran (THF), followed by sequential addition of potassium carbonate (306.8 $\mathrm{mg}$, $2.22 \mathrm{mmol}), 1.0 \mathrm{M}$ tetrabutylammonium fluoride (TBAF) solution in THF (122 $\mu \mathrm{L}, 0.44$ $\mathrm{mmol})$ and ethyl bromoacetate $(82 \mu \mathrm{L}, 0.74 \mathrm{mmol})$. The reaction was heated at $40{ }^{\circ} \mathrm{C}$. After $3 \mathrm{~h}$, another portion of TBAF $(122 \mu \mathrm{L}, 0.44 \mathrm{mmol})$ and ethyl bromoacetate $(82 \mu \mathrm{L}, 0.74$ $\mathrm{mmol}$ ) was added and continued heating at $40{ }^{\circ} \mathrm{C}$. The resultant product formation was monitored by TLC, ensuring complete conversion of the starting material (100\% yield). After completion, THF was removed under reduced pressure, and the glycolate product was 
extracted using ethyl acetate (EtOAc) and $\mathrm{H}_{2} \mathrm{O}$. The crude glycolate product was then dissolved in $6 \mathrm{~mL}$ of $\mathrm{THF} / \mathrm{H}_{2} \mathrm{O}$ (1:1) mixture. Sodium hydroxide (100 mg, $2.5 \mathrm{mmol}$ ) was added to the reaction mixture and stirred overnight at room temperature. The reaction mixture was concentrated by evaporating THF under reduced pressure. The resultant aqueous solution was acidified to $\mathrm{pH} 6.0$ by adding $1.0 \mathrm{M} \mathrm{HCl}$. Finally, the estrone glycolic acid product was extracted in EtOAc, and the aqueous phase was washed with EtOAc three times. The organic layers were combined and concentrated using a rotary evaporator to achieve the white solid product. ${ }^{1} \mathrm{H}-\mathrm{NMR}$ analysis of the obtained estrone glycolic acid derivative showed high purity with an overall yield of $90 \%$, and it was used for further conjugation. ${ }^{1} \mathrm{H}-\mathrm{NMR}: \delta 1.08(3 \mathrm{H}, \mathrm{s}), 1.38-1.79(8 \mathrm{H}, \mathrm{m}), 2.09-2.42(4 \mathrm{H}, \mathrm{m}), 2.60(1 \mathrm{H}$, ddd), 2.66-2.84 (2H, m), 4.45-4.46 (2H, s), $6.66(1 \mathrm{H}, \mathrm{dd}), 6.85(1 \mathrm{H}, \mathrm{dd}), 7.00(1 \mathrm{H}, \mathrm{dd}$,$) .$

The estrone glycolic acid derivative was conjugated with PEG diamine $\left(\mathrm{NH}_{2}-\mathrm{PEG}-\mathrm{NH}_{2}\right)$ using acid-amine coupling chemistry in the presence of HATU as the coupling reagent (Figure 2A, Step II). Briefly, estrone glycolic acid (10 mg, $0.030 \mathrm{mmol}$ ) was added to a vial and was dissolved in $1 \mathrm{~mL}$ of anhydrous acetonitrile (ACN) followed by the addition of triethylamine $(9.2 \mu \mathrm{L}, 0.066 \mathrm{mmol})$. HATU $(12 \mathrm{mg}, 0.0315 \mathrm{mmol})$ was dissolved in $0.5 \mathrm{~mL}$ of dry acetonitrile and then added to the reaction vial. The reaction mixture was stirred for $15 \mathrm{~min}$ at room temperature under dark conditions. $\mathrm{NH}_{2}-\mathrm{PEG}-\mathrm{NH}_{2}(102 \mathrm{mg}, 0.030 \mathrm{mmol})$ was added followed by the addition of $2 \mathrm{~mL}$ anhydrous ACN. The reaction was stirred overnight at room temperature. The reaction was monitored by TLC using $10 \%$ methanol $(\mathrm{MeOH})+1 \%$ ammonium hydroxide $(\mathrm{NH} 4 \mathrm{OH})$. After completion, $\mathrm{ACN}$ was removed under

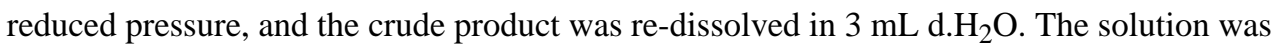
loaded into a dialysis bag (Spectra Por-3, MWCO 3500) and dialyzed against deionized water $(2 \times 2 \mathrm{~L}, 24 \mathrm{~h})$. The solution was lyophilized, and $90 \mathrm{mg}$ of $\mathrm{NH}_{2}$-PEG-Estrone conjugate was obtained. The obtained $\mathrm{NH}_{2}$-PEG-Estrone was analyzed using ${ }^{1} \mathrm{H}-\mathrm{NMR}$, demonstrating the characteristic conjugated estrone peaks from $\delta 6.8$ to $\delta 7.2 \mathrm{ppm}$.

\section{Synthesis of $\mathrm{NH}_{2}$-PEG-Progesterone}

The synthesis proceeded by synthesizing an aminooxy derivative of $\mathrm{PEG}^{55}$ due to the higher stability of the resultant oxime than that for the imine or hydrazone bonds at physiological conditions (Figure 3A, Step I). First, equimolar ratio of triphenylphosphine (0.308 g, 1.176 mmol) and N-hydroxyphthalimide $(0.191 \mathrm{~g}, 1.176 \mathrm{mmol})$ were dissolved in THF $(10 \mathrm{~mL})$ and cooled to $0^{\circ} \mathrm{C}$ under $\mathrm{N}_{2}$ atmosphere. PEG (3,400 Da) (1.0 g, 0.294 mmol) was added to the cooled reaction mass. In a separate vial, a solution of diisopropyl azodicarboxylate (DIAD) $(0.23 \mathrm{~mL}, 1.176 \mathrm{mmol})$ in THF $(2 \mathrm{~mL})$ was prepared and added dropwise to the abovementioned reaction mixture at $0{ }^{\circ} \mathrm{C}$. The reaction mixture was stirred overnight at room temperature. The reaction proceeded to completion in $12 \mathrm{~h}$. The crude reaction mixture was thereafter concentrated under reduced pressure. The crude material was purified by flash chromatography by initially removing all the side products using 70\% EtOAc: Hexane system, followed by using $10 \% \mathrm{MeOH}$ : DCM gradient to obtain pure bis-Nhydroxyphthalimide-PEG derivative with $70 \%$ yield. ${ }^{1} \mathrm{H}-\mathrm{NMR}\left(400 \mathrm{MHz}, \mathrm{CDCl}_{3}\right): \delta 7.83$ (m, 4H, Ar), 7.44 (m, 4H, Ar), 4.36 (t, 4H, $-\mathrm{CH}_{2}$ ), 3.85 (t, 4H, $-\mathrm{CH}_{2}$ ), 3.63 (bs, 284H, $-\mathrm{CH}_{2}$ ). 
Next, the bis-N-hydroxyphthalimide PEG product $(0.3 \mathrm{~g}, 0.081 \mathrm{mmol})$ was dissolved in DCM $(10 \mathrm{~mL})$. Hydrazine monohydrate $(0.033 \mathrm{~mL}, 0.813 \mathrm{mmol})$ was added to the reaction mixture and refluxed overnight. The solvent was removed under reduced pressure. The crude mass was dissolved in a minimum amount of water and transferred to a dialysis bag (Spectra Por-3, MWCO 3500) and dialyzed against deionized water $(2 \times 2 \mathrm{~L}, 24 \mathrm{~h})$. The aqueous layer was lyophilized to obtain the PEG-hydroxylamine derivative with $65 \%$ yield. ${ }^{1} \mathrm{H}-\mathrm{NMR}$ (400 $\mathrm{MHz}, \mathrm{D}_{2} \mathrm{O}$ ): $\delta 3.85$ (t, $4 \mathrm{H},-\mathrm{CH}_{2}$ ), 3.68 (bs, $284 \mathrm{H},-\mathrm{CH}_{2}$ ).

The purified PEG-hydroxylamine (100 mg, $0.029 \mathrm{mmol})$ was dissolved in $\mathrm{MeOH}(6 \mathrm{~mL})$ (Figure 3B, Step II). Progesterone $(36.67 \mathrm{mg}, 0.116 \mathrm{mmol})$ and a catalytic amount of TFA (1-2 drops) were added to this solution. The reaction mass was heated at $40{ }^{\circ} \mathrm{C}$ overnight. After completion, $\mathrm{MeOH}$ was removed under reduced pressure, and the crude product was re-dissolved in $3 \mathrm{~mL}$ d. $\mathrm{H}_{2} \mathrm{O}$. The solution was loaded into a dialysis bag (Spectra Por-3, MWCO 3500) and dialyzed against deionized water ( $2 \times 2 \mathrm{~L}, 24 \mathrm{~h})$. The solution was lyophilized to obtain $\mathrm{NH}_{2}$-PEG-progesterone conjugate with $90 \%$ yield. ${ }^{1} \mathrm{H}-\mathrm{NMR}$ (400 $\mathrm{MHz}, \mathrm{CDCl}_{3}$ ): $\delta 5.74$ (s, 0.74H, $\left.-\mathrm{CH}\right), 4.15\left(\mathrm{~m}, 4 \mathrm{H},-\mathrm{CH}_{2}\right), 3.64$ (bs, 315H, $\left.-\mathrm{CH}_{2}\right), \delta 3.0-0.5$ (Progesterone peak area with characteristic peaks $-\mathrm{CH}_{3}$ at $\delta 2.12, \delta 1.12$ and $\delta$ 0.6).

\section{Synthesis of MTMPPPCAs}

Engineered MTMPPPCAs using the PEGylated targeting moieties $\left(\mathrm{NH}_{2}\right.$-PEG-Estrone and $\mathrm{NH}_{2}$-PEG-Progesterone) were synthesized via a modified single emulsification method described in Salvador-Morales et al. ${ }^{50}$ Another batch of untargeted multiplexed patchy polymeric contrast agents (UTMPPPCAs) (i.e., without the targeting moieties) was synthesized using the same procedure. Both targeted and untargeted NPs contained ICG and SQ650, which formed the inner lining of the core of the NP and also served as PA reporters. Starting materials were freshly prepared in appropriate solvents prior to NP synthesis. NP synthesis involves organic and aqueous phases. The organic phase is composed of PLGA (10 $\mathrm{mg} / \mathrm{mL}$ in EtOAc), ICG $(6.66 \mathrm{mg} / \mathrm{mL}$ in $\mathrm{MeOH})$ and $\mathrm{SQ650}\left(10 \mathrm{mg} / \mathrm{mL}\right.$ in $\left.\mathrm{CHCl}_{3}\right)$, while the aqueous phase is made of $\mathrm{NH}_{2}$-PEG-Estrone $\left(1 \mathrm{mg} / \mathrm{mL}\right.$ in d. $\left.\mathrm{H}_{2} \mathrm{O}\right), \mathrm{NH}_{2}$-PEGProgesterone $\left(1 \mathrm{mg} / \mathrm{mL}\right.$ in d. $\left.\mathrm{H}_{2} \mathrm{O}\right), \mathrm{NH}_{2}-\mathrm{PEG}-\mathrm{NH}_{2}\left(1 \mathrm{mg} / \mathrm{mL}\right.$ in d. $\left.\mathrm{H}_{2} \mathrm{O}\right)$, and PVA $\left(\right.$ d. $\left.\mathrm{H}_{2} \mathrm{O}\right)$. MTMPPPCAs were synthesized via a stepwise fashion. Initially, an aqueous phase was prepared by mixing $\mathrm{NH}_{2}$-PEG-Estrone, $\mathrm{NH}_{2}$-PEG-Progesterone, $\mathrm{PVA}$, and $\mathrm{d}_{2} \mathrm{H}_{2} \mathrm{O}$ in a glass reaction beaker. Next, the organic phase was prepared separately, consisting of PLGA, ICG, SQ650, and MeOH. Finally, the organic phase was rapidly added to the aqueous phase, and the resultant suspension was mixed at $8000 \mathrm{rpm}$ for 4 min using a homogenizer (L5M-A). The aqueous phase of UTMPPPCAs was comprised of $\mathrm{NH}_{2}-\mathrm{PEG}-\mathrm{NH}_{2}, \mathrm{PVA}$, and d. $\mathrm{H}_{2} \mathrm{O}$, while the organic phase was composed of PLGA, ICG, SQ650, and MeOH. UTMPPPCAs were synthesized following the same procedure described above. The excess of water and remnants of solvents were removed by evaporation and centrifugation. The latter was performed using Amicon ${ }^{\circledR}$ ultra centrifugal filters with MWCO of 10,000 Da. The purified NP suspension was lyophilized to obtain the dried nanoparticles in quantitative yield, stored at $-20{ }^{\circ} \mathrm{C}$ and protected from light until further use. 


\section{Receptor specific binding affinity studies using SPR}

The binding affinity of $\mathrm{NH}_{2}$-PEG-Estrone and $\mathrm{NH}_{2}$-PEG-Progesterone was assessed with a Biacore T200 system. Full length recombinant human estrogen alpha receptor (FLER-a, $66.4 \mathrm{kDa}, \sim 0.32 \mathrm{mg} / \mathrm{mL}$ stock) and recombinant protein of human progesterone receptor (PGR, (98 kDa, $\sim 0.050 \mathrm{mg} / \mathrm{mL}$ stock) were used as ligands to take the SPR measurements. In the SPR experiment the FLER-a receptor and PGR receptor were covalently immobilized to flow cell 2 (FC2) of a CM5 sensor chip to 10,000 RU (response units) using standard amine coupling chemistry in the presence of $10 \mathrm{mM}$ sodium acetate buffer at $\mathrm{pH} 5.5$. Estrogen-related receptor beta (ERR- $\beta, 54.3 \mathrm{kDa}, \sim 0.25 \mathrm{mg} / \mathrm{ml}$ stock) and full length HER2 served as negative controls in the SPR experiment. Both ERR- $\beta$ and HER2 were captured on flow cell 3 (FC3) and flow cell 4 (FC4) of the same sensor chip using standard amine coupling chemistry. PBS-P (20 mM PBS buffer pH 7.4, $137 \mathrm{mM} \mathrm{NaCl}, 2.7 \mathrm{mM} \mathrm{KCl}, 0.05 \%$ $\mathrm{v} / \mathrm{v}$ surfactant $\mathrm{P} 20$ ) was used as the immobilization/capture running buffer. A similar procedure was followed to evaluate the binding affinity of $\mathrm{NH}_{2}$-PEG-Progesterone. ERR- $\beta$ and FLER-a served as negative controls.

Flow cell 1 (FC1) was used as the reference for FC2, FC3, and FC4. The reference FC1 had the same coupling chemistry as the active FCs (FC2, FC3, and FC4) but without any proteins. $\mathrm{NH}_{2}$-PEG-Estrone and $\mathrm{NH}_{2}$-PEG-Progesterone analyte molecules with concentrations ranging from $1.625 \mu \mathrm{M}$ to $50 \mu \mathrm{M}$ were injected into these immobilized receptors overnight at a flow rate of $50 \mu \mathrm{L} / \mathrm{min}$ in the presence of PBS-P buffer. After each injection, compounds were allowed to dissociate for $120 \mathrm{~s}$ before starting the next compound injection cycle. All targeting moieties were injected in triplicates. The contact and dissociation times used were $60 \mathrm{~s}$ and $600 \mathrm{~s}$, respectively. Binding affinities of $\mathrm{NH}_{2}$-PEGEstrone and $\mathrm{NH}_{2}$-PEG-Progesterone were determined after subtracting the non-specific binding to the reference surfaces and response values for the blank buffer injections (double reference subtraction). Theoretical maximum binding levels $\left(\mathrm{R}_{\max }\right)$ were calculated assuming 1:1 binding interactions, and each molecule's binding percentage was compared to its corresponding $\mathrm{R}_{\max }$ value. Molecules binding with more than $50 \%$ of the theoretical $R_{\max }$ values to FLER- $a$ receptor and PGR receptor were selected as primary hits.

For the $\mathrm{NH}_{2}$-PEG-Estrone sample, dose-dependent response experiments were measured for FLER- $\alpha$, ERR- $\beta$, and HER2 receptors immobilized on FC2, FC3 and FC4 using standard amine chemistry in the presence of $10 \mathrm{mM}$ sodium acetate buffer at $\mathrm{pH} 5.5$ to levels of $\sim 4900 \mathrm{RU}, \sim 4900 \mathrm{RU}$, and $1800 \mathrm{RU}$, respectively. Similarly, another dose-response experiment for $\mathrm{NH}_{2}$-PEG-Progesterone was recorded for PGR, ERR- $\beta$ and FLER-a receptors immobilized on FC2, FC3, and FC4 using standard amine chemistry in the presence of $10 \mathrm{mM}$ sodium acetate buffer at pH 5.5 to levels of $\sim 9650 \mathrm{RU}, \sim 4900 \mathrm{RU}$, and $\sim 2600 \mathrm{RU}$, respectively. Sensorgrams from the overnight kinetics were evaluated, assuming 1:1 kinetic binding for determining the $\mathrm{K}_{\mathrm{D}}$ values.

\section{Physico-chemical characterization of MTMPPPCAs}

Super-resolution Imaging - $100 \mu \mathrm{g}$ of Alexa Fluor 647 carboxylic acid and $100 \mu \mathrm{g}$ of Cy3B NHS Ester were covalently bound with $\mathrm{NH}_{2}$-PEG-Estrone and $\mathrm{NH}_{2}$-PEGProgesterone, respectively, using the EDC/NHS coupling reagent as described in 
Invitrogen's protocol. Unreactive dyes were removed by dialysis for $24 \mathrm{hrs}$. Next, MTMPPPCAs were synthesized using the labeled PEGylated targeting moieties. The MTMPPPCAs were immobilized on $35 \mathrm{~mm}$ round glass coverslips using ultrasound gel, then mounted in Attofluor chambers. The chamber was filled with a PCA/PCD-based STORM buffer ${ }^{56}$ and the top sealed with a second coverslip, allowing oxygen to be depleted inside the chamber. Imaging was performed using a Nikon CFI Apochromat $100 \mathrm{x} /$ 1.49 TIRF objective mounted on a Nikon Eclipse Ti-E inverted microscope. This microscope was equipped with a Perfect Focus System, $561 \mathrm{~nm}$ and $647 \mathrm{~nm}$ lasers at $500 \mathrm{~mW}$ each, and a Photometrics Evolve 512 EMCCD camera. Once the specimen was brought into focus, and the TIRF angle was established, the Perfect Focus System was engaged, and the laser power was brought up to maximum. Once steady blinking of the fluorophores was established, 20,000-25,000 frames were acquired for each dye, and ThunderSTORM ${ }^{57}$ was used for localization, drift correction, and visualization of the data.

Transmission Electron Microscopy (TEM)—The MTMPPPCAs' morphology was determined by placing $10 \mu \mathrm{L}$ of MTMPPPCAs' suspension on a copper-carbon grid followed by the addition of $10 \mu \mathrm{L}$ of uranyl acetate $(2 \% \mathrm{w} / \mathrm{v})$ for negative staining purposes. The samples were dried at room temperature overnight and protected from light. After thorough drying, the samples were examined with an FEI Talos TEM, operated at $80 \mathrm{kV}$ accelerating voltage.

Scanning Electron Microscopy (SEM)-The MTMPPPCAs' surface morphology was observed by SEM. Briefly, $10 \mu \mathrm{L}$ of MTMPPPCAs suspension was placed on a silicon wafer substrate, air-dried overnight, and coated with 60-40 Au-Pd. The samples were imaged with a Zeiss Ultra 60 FESEM operated at $1 \mathrm{kV}$.

Photoacoustic and optical absorption spectra-We imbedded three tubes filled with nanoparticles with ICG, nanoparticles with SQ650 and MTMPPPCAs, respectively, in an agar gel phantom, which was imaged by PACT at wavelengths ranging from $570 \mathrm{~nm}$ to $870 \mathrm{~nm}$. The wavelengths were generated by an OPO laser (Spitlight EVO III, Innolas, Inc.), which includes one pump laser and two OPO crystals. The fundamental wavelength of the pump laser is $1064 \mathrm{~nm}$. Its second harmonic wavelength $(532 \mathrm{~nm})$ pumped an NIR OPO to generate near infrared light $(680-1064 \mathrm{~nm})$; while its third harmonic wavelength $(355 \mathrm{~nm})$ pumped a VIS OPO to generate visible light (420-680 nm. Then the output wavelength can be switched between $660 \mathrm{~nm}$ and $780 \mathrm{~nm}$ by selecting the output from the corresponding OPO crystal. The PA signals of ICG and SQ650 were computed via spectral unmixing.

Absorption spectra of the nanoparticles with SQ650, nanoparticles with ICG and MTMPPPCA suspension were obtained on an Agilent Cary $60 \mathrm{UV}$-Vis spectrophotometer. The absorption coefficient at $\lambda_{\max }=650 \mathrm{~nm}$ (for SQ650) and $\lambda_{\max }=780 \mathrm{~nm}$ (for ICG) were evaluated to determine the dye encapsulation for both NPs.

Particle size and Zeta Potential-The dynamic light scattering (DLS) and zeta potential measurements were performed on a Malvern Zetasizer ZS (Nano-ZS90) instrument by dispersing the materials $(1 \mathrm{mg} / \mathrm{mL})$ in $1 \mathrm{X}$ PBS $(0.15 \mathrm{M}, \mathrm{pH} 7.4)$ at $25^{\circ} \mathrm{C}$. 


\section{Determination of the encapsulation efficiency (EE) of the PA reporters in the polymeric matrix}

The encapsulation efficiency of the PA receptors in the polymeric particles was determined by fluorescence spectroscopy. Prior to the sample measurements, calibration curves for pure ICG and SQ650 dyes were recorded. ICG samples were prepared in $\mathrm{d}_{\mathrm{H}} \mathrm{H}_{2} \mathrm{O}$ with concentrations ranging from $100 \mathrm{ng} / \mathrm{mL}$ to $1000 \mathrm{ng} / \mathrm{mL}$. Fluorescence peaks for ICG were recorded at the excitation $\left(\lambda_{\text {exc }}\right)$ wavelength of $780 \mathrm{~nm}$ and emission $\left(\lambda_{\mathrm{em}}\right)$ wavelength from 500 to $900 \mathrm{~nm}$. Resultant $\lambda_{\text {em }}$ values peaked at $806 \mathrm{~nm}$ were recorded. Based on the standard curve calculations, $\mathrm{R}^{2}$ for ICG was 0.997 , suggesting good linearity. In the case of $\mathrm{SQ650}$ dye, the samples were prepared in $\mathrm{MeOH}$ owing to its hydrophobic character. SQ650 sample concentrations ranged from $50 \mathrm{ng} / \mathrm{mL}$ to $400 \mathrm{ng} / \mathrm{mL}$ and were recorded at the $\lambda_{\text {exc }}=650 \mathrm{~nm}$ and $\lambda_{\text {em }}$ from 500 to $900 \mathrm{~nm}$, respectively. The $\mathrm{R}^{2}$ value for SQ650 standard curve was 0.999 . The subsequent dye encapsulation efficiency of the PA receptors in the polymeric matrix was calculated based on the standard curve equations for both ICG and SQ650. The resultant linear regression equation used to determine the encapsulation efficiency of ICG was $y=0.0914 \mathrm{X}+0.324$ (where, $\mathrm{y}=$ fluorescence of sample at $\lambda_{\mathrm{em}}=806$ $\mathrm{nm}$ and $\mathrm{X}=$ concentration of sample) and for SQ650 was $\mathrm{y}=343.350 \mathrm{X}+2.884$ (where, $\mathrm{y}=$ fluorescence of sample at $\lambda_{\mathrm{em}}=662 \mathrm{~nm}$ and $\mathrm{X}=$ concentration of sample). Targeted and untargeted polymeric samples of known concentrations were suspended in $0.1 \mathrm{M}$ sodium acetate buffer ( $\mathrm{pH}$ 5.0) for $3 \mathrm{~h}$ before the measurements to achieve the complete degradation of NPs. These samples were further centrifuged to obtain the released dyes in the supernatant as well as the residue. Fluorescence measurements obtained for these samples were used to determine the overall encapsulation efficiency using the standard calibration curves as mentioned above and equation 2 (SI, 1.2).

\section{In vitro cellular uptake studies}

T-47D cells and MDA-MB-231 cells were cultured in their respective mediums as per ATCC standard protocols. Cells were grown at $37{ }^{\circ} \mathrm{C}$ in a humidified atmosphere with $5 \% \mathrm{CO}_{2}$. Cell uptake studies were performed using fluorescence-activating cell sorting (FACS) analysis and confocal microscopy. Binding affinity studies using FACS analysis were performed by seeding $3 \times 10^{5}$ cells per well in a 24-well culture plate. The cells were incubated for $24 \mathrm{~h}$ at $37^{\circ} \mathrm{C}$. The cells were washed with $1 \times$ PBS after $24 \mathrm{~h}$. Thereafter, 500 $\mu \mathrm{l}$ of NP samples $(0.5 \mathrm{mg} / \mathrm{mL})$ in the complete medium was added to the cells and incubated for $24 \mathrm{~h}$. The samples then were added in triplicates. After the incubation, the cells were washed with $1 \times$ PBS and collected in individual tubes after trypsinization and centrifugation. The cells were further incubated with Zombie Violet ${ }^{\mathrm{TM}}$ dye for $30 \mathrm{~min}$ at room temperature. After incubation, the cells were washed with $1 \times$ PBS and fixed with $4 \%$ paraformaldehyde buffer. After fixation, the cells were dispersed in fresh FACS buffer and analyzed using BD FACS Aria cell sorter as per the manufacturer instructions. Median fluorescent intensities (MFI) were recorded and plotted against the log-transformed NP concentrations using the non-linear regression analysis in the Prism 7 software.

For the cellular uptake studies using confocal microscopy, $8 \times 10^{4}$ cells per well were seeded on glass coverslips placed in a 24 -well culture plate and allowed to attach at $37{ }^{\circ} \mathrm{C}$. After 24 $\mathrm{h}$ incubation, cells were washed thrice with $1 \times \mathrm{PBS}$ and incubated with $500 \mu \mathrm{l}$ of 
nanoparticle samples $(0.5 \mathrm{mg} / \mathrm{mL})$ in the complete medium for $24 \mathrm{~h}$. After that, cells were washed three times with $1 \times \mathrm{PBS}$ and incubated for $30 \mathrm{~min}$ at $37^{\circ} \mathrm{C}$ with $3 \mu \mathrm{M}$ CMPTX cell tracker dye. After incubation, cells were washed with $1 \times$ PBS and fixed with $4 \%$ paraformaldehyde. Cells were washed several times with $1 \times$ PBS before and after staining with DAPI. Finally, the coverslips were mounted on microscope slides and examined by confocal laser scanning microscopy to determine the overall cellular uptake of MTMPPPCAs and UTMPPPCAs.

\section{In vitro cytotoxicity studies of MTMPPPCAs}

The cell viability activity was measured using a CytoTox-Fluor ${ }^{\mathrm{TM}}$ cytotoxicity assay kit following the manufacturer protocol. Briefly, T-47D and MDA-MB-231 cells were seeded in 96-well black microplates $\left(1 \times 10^{4}\right.$ cells per well) and incubated at $37{ }^{\circ} \mathrm{C}$ for $24 \mathrm{~h}$ for cell attachment. Wells were divided into a quintuplet group for each NP concentration ranging from $2 \mathrm{mg} / \mathrm{mL}, 1 \mathrm{mg} / \mathrm{mL}, 0.5 \mathrm{mg} / \mathrm{mL}, 0.25 \mathrm{mg} / \mathrm{mL}$, and $0.125 \mathrm{mg} / \mathrm{mL}$. The entire set of experiments was performed in three independent studies to evaluate the experimental variability. Viability assay was evaluated for all concentrations at $24 \mathrm{~h}$ time point following the manufacture guidelines. The percentile of cell viability was calculated using the resultant fluorescence values for each sample concentration. The standard equation for determining the cell viability percentile is provided in the SI equation 1 .

\section{In vivo MTMPPPCAs tumor internalization study using an orthotopic cell-derived xenograft breast cancer model}

Athymic nude female mice bearing T-47D or MDA-MB-231 tumors were divided into two groups (six mice/group) based on the targeted or untargeted dose injected into the mice. The NP formulations were dissolved in sterile $1 \times \mathrm{PBS}(\mathrm{pH}$ 7.4) prior to the injections. The in vivo biodistribution profile was determined by administering a combination dose $(1200 \mu \mathrm{g})$ of Targeted Nanoparticles (TNP) + SQ650 + Estrone (400 $\mu \mathrm{g})$, TNP + SQ650 + ICG + Estrone $(400 \mu \mathrm{g})$ and TNP + SQ650 + ICG + Progesterone + Estrone $(400 \mu \mathrm{g})$. Similarly, a combination dose of UTMPPPCAs comprised of Untargeted NP (UNP) + SQ650 (400 $\mu \mathrm{g})$, $\mathrm{UNP}+\mathrm{ICG}(400 \mu \mathrm{g})$ and UNP + SQ650 + ICG $(400 \mu \mathrm{g})$ was administered intravenously into the mice. One hundred $\mu \mathrm{l}$ of targeted or untargeted doses were injected into tumorbearing mice via tail-vein injection. The mice were imaged by IVIS before (baseline) and post-injection at time points of 1,3 and $6 \mathrm{~h}$. The excitation and emission wavelengths of 675 $\mathrm{nm}, 694 \mathrm{~nm}$ were used for SQ650, and $745 \mathrm{~nm}, 810 \mathrm{~nm}$ for ICG. The mice were euthanized after the $6 \mathrm{~h}$ post-injection following the animal ethic committee regulations. Ex vivo fluorescence imaging of organs, including tumors, livers, spleens, kidneys, hearts, urinary bladders, and lungs, were analyzed using IVIS for determining the nanoparticle uptake.

\section{Estrogen and progesterone receptor immunofluorescence staining}

For pathology studies, T-47D mouse orthotopic xenografts ex vivo tumors with MTMPPPCAs and UTMPPPCAs were immediately stored in 10\% formalin solution at room temperature after ex vivo fluorescence imaging. All the tumor tissue samples were analyzed for immunohistochemistry (IHC) using the estrogen receptor one (ESR1) and progesterone receptor (PR) antibodies. Breast cancer cells present in the tissue samples were identified using the hematoxylin and eosin (H\&E) stain. All tissue samples were processed and 
embedded with the largest surface area of the tumor down, mimicking the conditions for obtaining the fluorescent radiographs. All paraffin-embedded tumor tissue samples were sectioned at $4 \mu \mathrm{m}$ thickness onto positively charged slides. After imaging the full tissue, 10 serial sections were collected for further staining to localize the estrogen and progesterone receptors.

IHC optimization for ESR1 receptor was performed on the formalin-fixed paraffinembedded (FPPE) human breast carcinoma tissue using a Leica Bond automated immunostainer and a rabbit anti-ESR1 antibody. Heat-induced antigen retrieval was performed using the Leica Bond Epitope Retrieval Buffer (Citrate solution, $\mathrm{pH}$ 6.0) for 20 min. Endogenous peroxides were blocked using the BloxAll (Vector Labs, SP-6000) for 20 min, followed by washing the tissue sections with buffer solution. Non-specific antibody binding was blocked using the Novolink protein block (Leica, RE7280-CE) for $30 \mathrm{~min}$, prior to the addition of the primary antibody. After $30 \mathrm{~min}$ of incubation with the primary antibody, the tumor sections were incubated with anti-rabbit Poly-HRP-IgG secondary antibody (Leica, RE7280-CE) for $15 \mathrm{~min}$. Anti-ESR1 antibody was detected using Novocastra Bond Refine Polymer Detection and visualized with 3'3-diaminobenzidine stain as brown spots After the optimization process, the slides were examined, and the optimal conditions to detect the antigen of interest were determined. It was found that a dilution of 1:100 and citrate $\mathrm{pH} 6.0$ or antigen retrieval are the best conditions.

Similarly, the optimization of the PR receptor using IHC was performed on the FPPE human prostate tissue using a Leica Bond automated immunostainer and a rabbit anti-PR antibody. The optimization process for the detection of PR receptor in the tumor began at 1:100, 1:250 and 1:500. The rest of the procedure was the same as the one used for the detection of the estrogen receptor. It was found that the ideal dilution to detect PR was 1:100. PR+ positive cells appear as brown spots.

\section{The H\&E staining}

The procedure was initiated by dewaxing the tumor tissue sections in xylene, followed by washing with $100 \% \mathrm{EtOH}$ and then hydrating with $95 \% \mathrm{EtOH}$. The sections were rinsed twice with distilled water and incubated with the hematoxylin stain. After incubation, the sections were rinsed with running tap water and kept in the bluing solution for 10s. These stained tissue sections were then rinsed with running tap water and placed in $95 \% \mathrm{EtOH}$ for $1 \mathrm{~min}$. Eosin staining was performed subsequently, followed by gradual dehydration of the stained tissues using $95 \%$ to $100 \%$ EtOH. Finally, the sections were cleared in xylene and mounted with permaslip to obtain the images.

\section{PA measurements}

Mapping the ITH in tumors ex vivo was conducted using the SIP-PACT system. ${ }^{41}$ The SIPPACT system employed a 512-element full-ring ultrasonic transducer array for 2D panoramic acoustic detection. A lab-made 512-channel preamplifier was directly connected to the ultrasonic transducer array housing to minimize cable noise. The pre-amplified PA signals were digitized using a 512-channel data acquisition system. The digitized radio frequency data were first stored in the onboard buffer, then transferred to a computer and 
reconstructed using the dual-speed-of-sound half-time universal back-projection algorithm.

29, 41 The engineered MTMPPPCAs have two absorption peaks at $660 \mathrm{~nm}$ and $780 \mathrm{~nm}$, respectively, thus the ex vivo PA measurements were carried out at $660 \mathrm{~nm}$ and $780 \mathrm{~nm}$.

\section{Hemolytic assay}

The Hemolytic assay was performed as described by Neun B. et al. ${ }^{58-60}$ This is a quantitative colorimetric assay to determine plasma free hemoglobin (PFH) and total hemoglobin in whole blood (TBH). In the first step, the levels of hemoglobin in a female human plasma sample were determined to assure that no hemolysis occurred in the whole blood sample before the experiment. Thus, a calibration curve was prepared for this purpose. Briefly, $3 \mathrm{ml}$ of female human fresh blood were centrifuged at $800 \mathrm{x}$ g for $15 \mathrm{~min}$. The supernatant was collected to determine the levels of hemoglobin in plasma which was performed by preparing a calibration curve with calibration standards, quality controls and control samples. Two hundred microliters of each calibration standard, quality control, and blank (Cyanmethemoglobin (CMH)) were placed in a 96 well plate. Triplicates were used for each sample. Two hundred ul of a total blood hemoglobin (THB) sample was prepared by mixing $20 \mathrm{ul}$ of whole blood and $5.0 \mathrm{ml}$ of CMH reagent and two hundred ul of this mixture were placed in each well. Samples were prepared in sextuples. One hundred ul of plasma free hemoglobin were placed in a 96 well plate followed by $100 \mathrm{ul}$ of $\mathrm{CMH}$ to make a final volume of $200 \mathrm{ul}$ in each well. The absorbance was measured at $540 \mathrm{~nm}$ to determine the hemoglobin concentration in the plasma sample.

In the second step, the hemolysis percent caused by MTMPPPCAs was determined. The MTMPPPCAs were incubated with Total Blood Hemoglobin, diluted (TBHd) and without TBHd. Positive and negative controls were included in the experiment. The positive control samples were prepared by incubating TBHd samples with Triton X-100 $(10 \mathrm{mg} / \mathrm{ml})$, whereas the negative control samples consisted of incubating the TBHd samples in $\mathrm{Ca}^{2+} /$ $\mathrm{Mg}^{2+}$-free PBS. The samples were placed in a water bath for $31 / 4 \mathrm{hrs}$ followed by centrifugation at $800 \mathrm{xg}$ for $15 \mathrm{~min}$. The samples were mixed every $30 \mathrm{~min}$. A fresh set of calibration and quality controls were prepared to determine the hemolysis caused by the presence of MTMPPPCAs in the samples incubated with TBHd. Subsequently, the absorbance was read at $540 \mathrm{~nm}$ to determine the samples' hemoglobin concentration.

\section{Liver pathology studies}

Three frozen mouse liver samples (livers from the untargeted, targeted and control mouse (i.e., no MTMPPPCAs administration)) derived from the ex vivo animal studies were sectioned and stained with hematoxylin \& Eosin according to Reveal Bioscience's protocol. The samples were subjected to pathology studies.

\section{Supplementary Material}

Refer to Web version on PubMed Central for supplementary material. 


\section{ACKNOWLEDGMENT}

This research was supported by the National Institutes of Health, Center for Innovative Technology (CIT) and National Science Foundation (NSF)-I Corp program under Grants R15CA213093-01A1, MF17-020-LS, 1756062 (all to C.S.M). This work was sponsored by the NIH grants EB016986 (Pioneer Award), CA186567 (Transformative Research Award), NS090579, NS099717, EB016963 (all to L.V.W.).

\section{REFERENCES}

1. Bray F; Ferlay J; Soerjomataram I; Siegel RL; Torre LA; Jemal A, Global Cancer Statistics 2018: GLOBOCAN Estimates of Incidence and Mortality Worldwide for 36 Cancers in 185 Countries. CA Cancer J Clin. 2018, 68, 394-424. [PubMed: 30207593]

2. Cronin KA; Lake AJ; Scott S; Sherman RL; Noone AM; Howlader N; Henley SJ; Anderson RN; Firth AU; Ma JM; Kohler BA; Jemal A, Annual Report to the Nation on the Status of Cancer, Part I: National Cancer Statistics. Cancer 2018, 124, 2785-2800. [PubMed: 29786848]

3. Joseph C; Papadaki A; Althobiti M; Alsaleem M; Aleskandarany MA; Rakha EA, Breast Cancer Intratumour Heterogeneity: Current Status and Clinical Implications. Histopathology2018, 73, 717 731. [PubMed: 29722058]

4. Tanas AS; Sigin VO; Kalinkin AI; Litviakov NV; Slonimskaya EM; Ibragimova MK; Ignatova EO; Simonova OA; Kuznetsova EB; Kekeeva TV; Larin SS; Poddubskaya EV; Trotsenko ID; Rudenko VV; Karandasheva KO; Petrova KD; Tsyganov MM; Deryusheva IV; Kazantseva PV; Doroshenko AV et al., Genome-Wide Methylotyping Resolves Breast Cancer Epigenetic Heterogeneity and Suggests Novel Therapeutic Perspectives. Epigenomics 2019, 11, 605-617. [PubMed: 30729807]

5. Turashvili G; Brogi E, Tumor Heterogeneity in Breast Cancer. Front. Med 2017, 4, 1-11.

6. American Cancer Society. Breast Cancer Facts \& Figures 2019-2020. 2019, https://www.cancer.org/ content/dam/cancer-org/research/cancer-facts-and-statistics/breast-cancer-facts-and-figures/breastcancer-facts-and-figures-2019-2020 (accessed March, 11, 2020).

7. Sinn HP; Kreipe H, A Brief Overview of the WHO Classification of Breast Tumors, 4th Edition, Focusing on Issues and Updates from the 3rd Edition. Breast Care 2013, 8, 149-154. [PubMed: 24415964]

8. Fragomeni SM; Sciallis A; Jeruss JS, Molecular Subtypes and Local-Regional Control of Breast Cancer. Surg. Oncol. Clin. N. Am 2018, 27, 95-120. [PubMed: 29132568]

9. Dai X; Xiang L; Li T; Bai Z, Cancer Hallmarks, Biomarkers and Breast Cancer Molecular Subtypes. J. Cancer 2016, 7, 1281-94. [PubMed: 27390604]

10. Gao JJ; Swain SM, Luminal A Breast Cancer and Molecular Assays: A Review. Oncologist 2018, 23, 556-565. [PubMed: 29472313]

11. Bertucci F; Finetti P; Goncalves A; Birnbaum D, The Therapeutic Response of ER+/HER2- Breast Cancers Differs According to the Molecular Basal or Luminal Subtype. NPJ Breast Cancer 2020, 6, 1-8. [PubMed: 31934613]

12. Schettini F; Pascual T; Conte B; Chic N; Braso-Maristany F; Galvan P; Martinez O; Adamo B; Vidal M; Munoz M; Fernandez-Martinez A; Rognoni C; Griguolo G; Guarneri V; Conte PF; Locci M; Brase JC; Gonzalez-Farre B; Villagrasa P; De Placido S; et al., HER2-Enriched Subtype and Pathological Complete Response in HER2-Positive Breast Cancer: A Systematic Review and Meta-Analysis. Cancer Treat. Rev 2020, 84, 101965. [PubMed: 32000054]

13. Krasniqi E; Barchiesi G; Pizzuti L; Mazzotta M; Venuti A; Maugeri-Sacca M; Sanguineti G; Massimiani G; Sergi D; Carpano S; Marchetti P; Tomao S; Gamucci T; De Maria R; Tomao F; Natoli C; Tinari N; Ciliberto G; Barba M; Vici P, Immunotherapy in HER2-Positive Breast Cancer: State of the Art and Future Perspectives. J. Hematol. Oncol 2019, 12, 1-26. [PubMed: 30606227]

14. Zhao S; Zuo WJ; Shao ZM; Jiang YZ, Molecular Subtypes and Precision Treatment of TripleNegative Breast Cancer. Ann. Transl. Med 2020, 8, 1-14. [PubMed: 32055592]

15. Lee J; Yost S; Yuan Y, Neoadjuvant Treatment for Triple Negative Breast Cancer: Recent Progresses and Challenges. Cancers 2020, 12, 1-20.

16. Schmitz J; Schwab J; Schwenck J; Chen Q; Quintanilla-Martinez L; Hahn M; Wietek B; Schwenzer N; Staebler A; Kohlhofer U; Aina OH; Hubbard NE; Reischl G; Borowsky AD; 
Brucker S; Nikolaou K; la Fougere C; Cardiff RD; Pichler BJ; Schmid AM, Decoding Intratumoral Heterogeneity of Breast Cancer by Multiparametric in Vivo Imaging: A Translational Study. Cancer Res. 2016, 76, 5512-5522. [PubMed: 27466286]

17. Bailly C; Bodet-Milin C; Bourgeois M; Gouard S; Ansquer C; Barbaud M; Sebille JC; Cherel M; Kraeber-Bodere F; Cartier T, Exploring Tumor Heterogeneity Using PET Imaging: The Big Picture. Cancers 2019, 11, 1-17.

18. Molina-Garcia D; Garcia-Vicente AM; Perez-Beteta J; Amo-Salas M; Martinez-Gonzalez A; TelloGalan MJ; Soriano-Castrejon A; Perez-Garcia VM, Intratumoral Heterogeneity in ${ }^{18}$ F-FDG PET/CT by Textural Analysis in Breast Cancer as a Predictive and Prognostic Subrogate. Ann. Nucl. Med 2018, 32, 379-388. [PubMed: 29869770]

19. Yoon HJ; Kim Y; Chung J; Kim BS, Predicting Neo-Adjuvant Chemotherapy Response and Progression-Free Survival of Locally Advanced Breast Cancer Using Textural Features of Intratumoral Heterogeneity on F-18 FDG PET/CT and Diffusion-Weighted MR Imaging. Breast J. 2019, 25, 373-380. [PubMed: 29602210]

20. Schelhaas S; Heinzmann K; Bollineni VR; Kramer GM; Liu Y; Waterton JC; Aboagye EO; Shields AF; Soloviev D; Jacobs AH, Preclinical Applications of 3 '-Deoxy-3 '- $\left[{ }^{18}\right.$ F] Fluoro-Thymidine in Oncology- A Systematic Review. Theranostics 2017, 7 40-50. [PubMed: 28042315]

21. Liao GJ; Clark AS; Schubert EK; Mankoff DA, F-18-Fluoroestradiol PET: Current Status and Potential Future Clinical Applications. J. Nucl. Med 2016, 57, 1269-1275. [PubMed: 27307345]

22. Groheux D; Martineau A; Teixeira L; Espie M; de Cremoux P; Bertheau P; Merlet P; Lemarignier $\mathrm{C},{ }^{18}$ FDG-PET/CT for Predicting the Outcome in ER+/HER2- Breast Cancer Patients: Comparison of Clinicopathological Parameters and PET Image-Derived Indices Including Tumor Texture Analysis. Breast Cancer Res. 2017, 19, 3, 1-10. [PubMed: 28052757]

23. Yildirim N; Simsek M; Aldemir MN; Bilici M; Tekin SB, Relationship Between 18-FDG-PET/CT and Clinicopathological Features and Pathological Responses in Patients with Locally Advanced Breast Cancers. Eurasian J. Med 2019, 51, 154-159. [PubMed: 31258356]

24. Groheux D; Cochet A; Humbert O; Alberini JL; Hindie E; Mankoff D, ${ }^{18}$ F-FDG PET/CT for Staging and Restaging of Breast Cancer. J. Nucl. Med 2016, 57, 17S-26S. [PubMed: 26834096]

25. Adejolu M; Huo L; Rohren E; Santiago L; Yang WT, False-Positive Lesions Mimicking Breast Cancer on FDG PET and PET/CT. AJR Am. J. Roentgenol 2012, 198, W304-W314. [PubMed: 22358030]

26. Yamamoto S; Yamagishi S; Kohno T; Tajiri R; Gondo T; Fujii Y; Tsukamoto H, Maximum Standardized Uptake Value of ${ }^{18}$ F-Fluorodeoxyglucose Positron Emission Tomography/Computed Tomography Could Replace Pathological Diagnosis in Luminal Breast Cancer. Ann. Breast Surg 2019, 3, 5, 1410-1418.

27. Li L; Shemetov AA; Baloban M; Hu P; Zhu LR; Shcherbakova DM; Zhang RY; Shi JH; Yao JJ; Wang LHV; Verkhusha VV, Small Near-Infrared Photochromic Protein for Photoacoustic MultiContrast Imaging and Detection of Protein Interactions in Vivo. Nat. Commun 2018, 9, 2734, 114. [PubMed: 29317637]

28. Hai PF; Imai T; Xu S; Zhang RY; Aft RL; Zou J; Wang LHV, High-Throughput, Label-Free, Single-Cell Photoacoustic Microscopy of Intratumoral Metabolic Heterogeneity. Nat. Biomed. Eng 2019, 3, 381-391. [PubMed: 30936431]

29. Wu ZG; Li L; Yang YR; Hu P; Li Y; Yang SYO; Wang LV; Gao W, A Microrobotic System Guided by Photoacoustic Computed Tomography for Targeted Navigation in Intestines in Vivo. Sci. Robot 2019, 4, eaax0613, 1-20. [PubMed: 32632399]

30. Yao JJ; Kaberniuk AA; Li L; Shcherbakova DM; Zhang RY; Wang LD; Li G; Verkhusha VV; Wang LHV, Multiscale Photoacoustic Tomography Using Reversibly Switchable Bacterial Phytochrome as a Near-Infrared Photochromic Probe. Nat. Methods 2016, 13, 67-73. [PubMed: 26550774]

31. Weber J; Beard PC; Bohndiek SE, Contrast Agents for Molecular Photoacoustic Imaging. Nat. Methods 2016, 13, 639-650. [PubMed: 27467727]

32. Bao X; Yuan Y; Chen J; Zhang B; Li D; Zhou D; Jing P; Xu G; Wang Y; Holá K; Shen D; Wu C; Song L; Liu C; Zbořil R; Qu S, in Vivo Theranostics with Near-Infrared-Emitting Carbon Dots- 
Highly Efficient Photothermal Therapy Based on Passive Targeting After Intravenous Administration. Light Sci. Appl 2018, 7, 91, 1-11. [PubMed: 30839587]

33. Li L; Zhu LR; Shen YC; Wang LVH, Multiview Hilbert Transformation in Full-Ring Transducer Array-Based Photoacoustic Computed Tomography. J. Biomed. Opt 2017, 22, 076017-1-076017-7.

34. Steinberg I; Huland DM; Vermesh O; Frostig HE; Tummers WS; Gambhir SS, Photoacoustic Clinical Imaging. Photoacoustics 2019, 14, 77-98. [PubMed: 31293884]

35. Wang LHV; Yao JJ, A Practical Guide to Photoacoustic Tomography in The Life Sciences. Nat. Methods 2016, 13, 627-638. [PubMed: 27467726]

36. Li Y; Li L; Zhu LR; Maslov K; Shi JH; Hu P; Bo E; Yao JJ; Liang JY; Wang LD; Wang LHV, Snapshot Photoacoustic Topography Through an Ergodic Relay for High-Throughput Imaging of Optical Absorption. Nat. Photonics 2020, 14, 164-170.

37. Razansky D; Distel M; Vinegoni C; Ma R; Perrimon N; Koster RW; Ntziachristos V, Multispectral Opto-Acoustic Tomography of Deep-Seated Fluorescent Proteins in Vivo. Nat. Photonics 2009, 3 , 412-417.

38. Li L; Xia J; Li G; Garcia-Uribe A; Sheng QW; Anastasio MA; Wang LV, Label-Free Photoacoustic Tomography of Whole Mouse Brain Structures ex Vivo. Neurophotonics 2016, 3, 035001-1-035001-8.

39. Shi JH; Wong TTW; He Y; Li L; Zhang RY; Yung CS; Hwang J; Maslov K; Wang LHV, HighResolution, High-Contrast Mid-Infrared Imaging of Fresh Biological Samples with UltravioletLocalized Photoacoustic Microscopy. Nat. Photonics 2019, 13, 609-615. [PubMed: 31440304]

40. Beard P, Biomedical Photoacoustic Imaging. interface Focus 2011, 1, 602-631. [PubMed: 22866233]

41. Li L; Zhu LR; Ma C; Lin L; Yao JJ; Wang LD; Maslov K; Zhang RY; Chen WY; Shi JH; Wang LHV, Single-Impulse Panoramic Photoacoustic Computed Tomography of Small-Animal WholeBody Dynamics at High Spatiotemporal Resolution. Nat. Biomed. Eng 2017, 1, 0071, 1-26.

42. Lin L; Hu P; Shi JH; Appleton CM; Maslov K; Li L; Zhang RY; Wang LHV, Single-Breath-Hold Photoacoustic Computed Tomography of the Breast. Nat. Commun 2018, 9, 1-9. [PubMed: 29317637]

43. Toi M; Asao Y; Matsumoto Y; Sekiguchi H; Yoshikawa A; Takada M; Kataoka M; Endo T; Kawaguchi-Sakita N; Kawashima M; Fakhrejahani E; Kanao S; Yamaga I; Nakayama Y; Tokiwa M; Torii M; Yagi T; Sakurai T; Togashi K; Shiina T, Visualization of Tumor-Related Blood Vessels in Human Breast by Photoacoustic Imaging System with a Hemispherical Detector Array. Sci. Rep 2017, 7, 1-11. [PubMed: 28127051]

44. Diot G; Metz S; Noske A; Liapis E; Schroeder B; Ovsepian SV; Meier R; Rummeny E; Ntziachristos V, Multispectral Optoacoustic Tomography (MSOT) of Human Breast Cancer. Clin. Cancer Res 2017, 23, 6912-6922. [PubMed: 28899968]

45. Dogan BE; Menezes GLG; Butler RS; Neuschler EI; Aitchison R; Lavin PT; Tucker EL; Grobmyer SR; Otto PM; Stavros AT, Optoacoustic Imaging and Gray-Scale US Features of Breast Cancers: Correlation with Molecular Subtypes. Radiology 2019, 292, 564-572. [PubMed: 31287388]

46. Menezes GLG; Mann RM; Meeuwis C; Bisschops B; Veltman J; Lavin PT; van de Vijver MJ; Pijnappel RM, Optoacoustic Imaging of the Breast: Correlation with Histopathology and Histopathologic Biomarkers. Eur Radiol. 2019, 29, 6728-6740. [PubMed: 31134367]

47. Wilson KE; Bachawal SV; Willmann JK, Intraoperative Resection Guidance with Photoacoustic and Fluorescence Molecular Imaging Using an Anti-B7-H3 Antibody-Indocyanine Green Dual Contrast Agent. Clin. Cancer Res 2018, 24, 3572-3582. [PubMed: 29712688]

48. Deng LM; Cai XJ; Sheng DL; Yang Y; Strohm EM; Wang ZG; Ran HT; Wang D; Zheng YY; Li P; Shang TT; Ling Y; Wang FJ; Sun Y, A Laser-Activated Biocompatible Theranostic Nanoagent for Targeted Multimodal Imaging and Photothermal Therapy. Theranostics 2017, 7, 4410-4423. [PubMed: 29158836]

49. Feng J; Xu Z; Luo D; Liu X, Multiplexed Imaging with Coordination Nanoparticles for Cancer Diagnosis and Therapy. ACS Appl. Bio Mater 2020, 3, 713-720.

50. Salvador-Morales C; Brahmbhatt B; Marquez-Miranda V; Araya-Duran I; Canan J; Gonzalez-Nilo F; Vilos C; Cebral J; Mut F; Lohner R; Leong B; Sundaresan G; Zweit J, Mechanistic Studies on 
the Self-Assembly of PLGA Patchy Particles and Their Potential Applications in Biomedical Imaging. Langmuir 2016, 32, 7929-7942. [PubMed: 27468612]

51. Rasheed N; Khorasani AA; Cebral J; Mut F; Lohner R; Salvador-Morales C, Mechanisms Involved in the Formation of Biocompatible Lipid Polymeric Hollow Patchy Particles. Langmuir 2015, 31, 6639-6648. [PubMed: 26057588]

52. Salvador-Morales C; Valencia PM; Gao W; Karnik R; Farokhzad OC, Spontaneous Formation of Heterogeneous Patches on Polymer-Lipid Core-Shell Particle Surfaces During Self-Assembly. Small (Weinheim an der Bergstrasse, Germany) 2013, 9, 511-517.

53. Werner JPF; Huang Y; Mishra K; Chmyrov A; Ntziachristos V; Stiel AC, Challenging a Preconception: Optoacoustic Spectrum Differs from the Absorption Spectrum of Proteins and Dyes for Molecular Imaging. BioRxiv 2020, 1-27. https://www.biorxiv.org/content/ 10.1101/2020.02.01.930230v1(accessed December 22, 2020).

54. Khopkar S; Deshpande S; Shankarling G, Greener Protocol for the Synthesis of NIR Fluorescent Indolenine-Based Symmetrical Squaraine Colorants. ACS Sustainable Chem. Eng 2018, 6, 1079810805.

55. Collins J; Xiao ZY; Connal LA, Tunable Degradation of Polyethylene Glycol-Like Polymers Based on Imine and Oxime Bonds. J. Polym. Sci. A Polym. Chem 2017, 55.3826-3831.

56. Olivier N; Keller D; Gönczy P; Manley S, Resolution Doubling in 3D-STORM Imaging Through Improved Buffers. PloS one. 2013, 8, e69004, 1-9. [PubMed: 23874848]

57. Ovesný M; Kř́žzek P; Borkovec J; Švindrych Z, Hagen GM. ThunderSTORM: A Comprehensive ImageJ Plugin for PALM and STORM Data Analysis and Super-Resolution Imaging. Bioinformatics. 2014, 30, 2389-2390. [PubMed: 24771516]

58. Neu BW; Cedrone E; Dobrovolskaia MA., NCL Method ITA-1: Analysis of Hemolytic Properties of Nanoparticles. National Characterization Lab: Frederick, Maryland, 2020;1-17.

59. ASTM Standard Practice F 756-00. Assessment of Hemolytic Properties of Materials.

60. ASTM E2524-08 (2013) Standard Test Method for Analysis of Hemolytic Properties of Nanoparticles. 


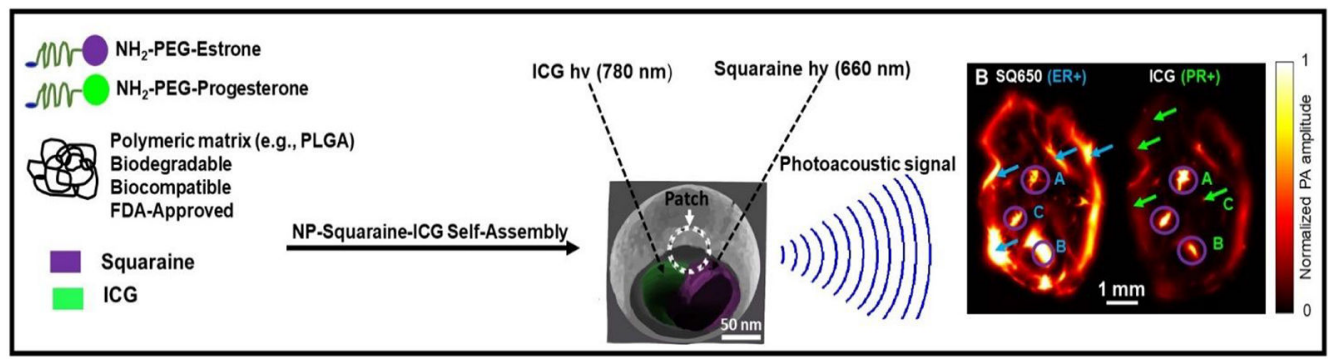

Figure 1.

Design and functionality of MTMPPPCAs. The surface and patch of MTMPPPCAs were functionalized with $\mathrm{NH}_{2}$-PEG-Estrone, $\mathrm{NH}_{2}$-PEG-Progesterone. SQ650 and ICG formed the inner lining of MTMPPPCAs' core. The MTMPPPCAs exhibited two optical absorption peaks at $660 \mathrm{~nm}$ and $780 \mathrm{~nm}$, respectively. Each absorption peak was linked to a specific targeting moiety. For example, the absorption peak at $660 \mathrm{~nm}$ indicates the specific binding of MTMPPPCAs functionalized with $\mathrm{NH}_{2}$-PEG-Estrone to the Estrogen receptor. 


\section{A $\mathrm{NH}_{2}$-PEG-Estrone}
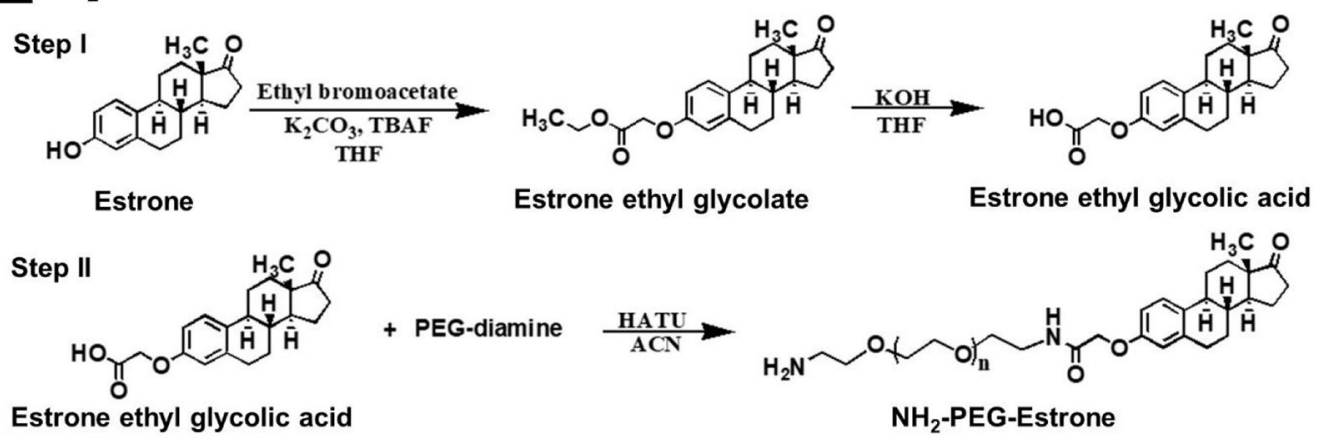

B

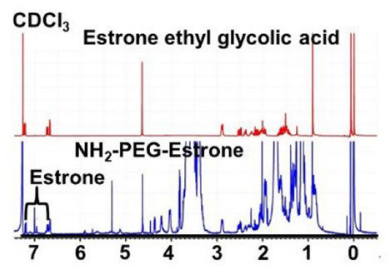

C

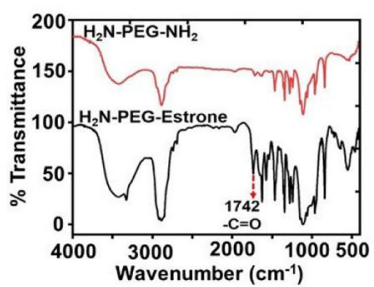

D

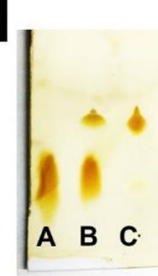

Figure 2.

(A) Stepwise methodology for the synthesis of $\mathrm{NH}_{2}$-PEG-Estrone. Step I. Synthesis of Estrone ethyl glycolic acid. Conditions: (1) Ethyl bromoacetate, $\mathrm{K}_{2} \mathrm{CO}_{3}$, TBAF, THF, $\mathrm{HCl}$, $40{ }^{\circ} \mathrm{C}$, overnight. (2) $\mathrm{KOH}$, THF: $\mathrm{H}_{2} \mathrm{O}$ (1:1), room temperature, overnight. Step II. Synthesis of $\mathrm{NH}_{2}$-PEG-Estrone. Conditions: HATU, anhydrous conditions. ACN, room temperature, overnight. Chemical characterization of PEGylated targeting moieties. (B) $\mathrm{NH}_{2}$-PEGEstrone ${ }^{1} \mathrm{H}-\mathrm{NMR}$. C. FTIR. D. TLC ((A): Estrone ethyl glycolic acid, (B): Co-spot, (C): $\mathrm{NH}_{2}$-PEG-Estrone). 


\section{A $\mathrm{NH}_{2}$-PEG-Progesterone}

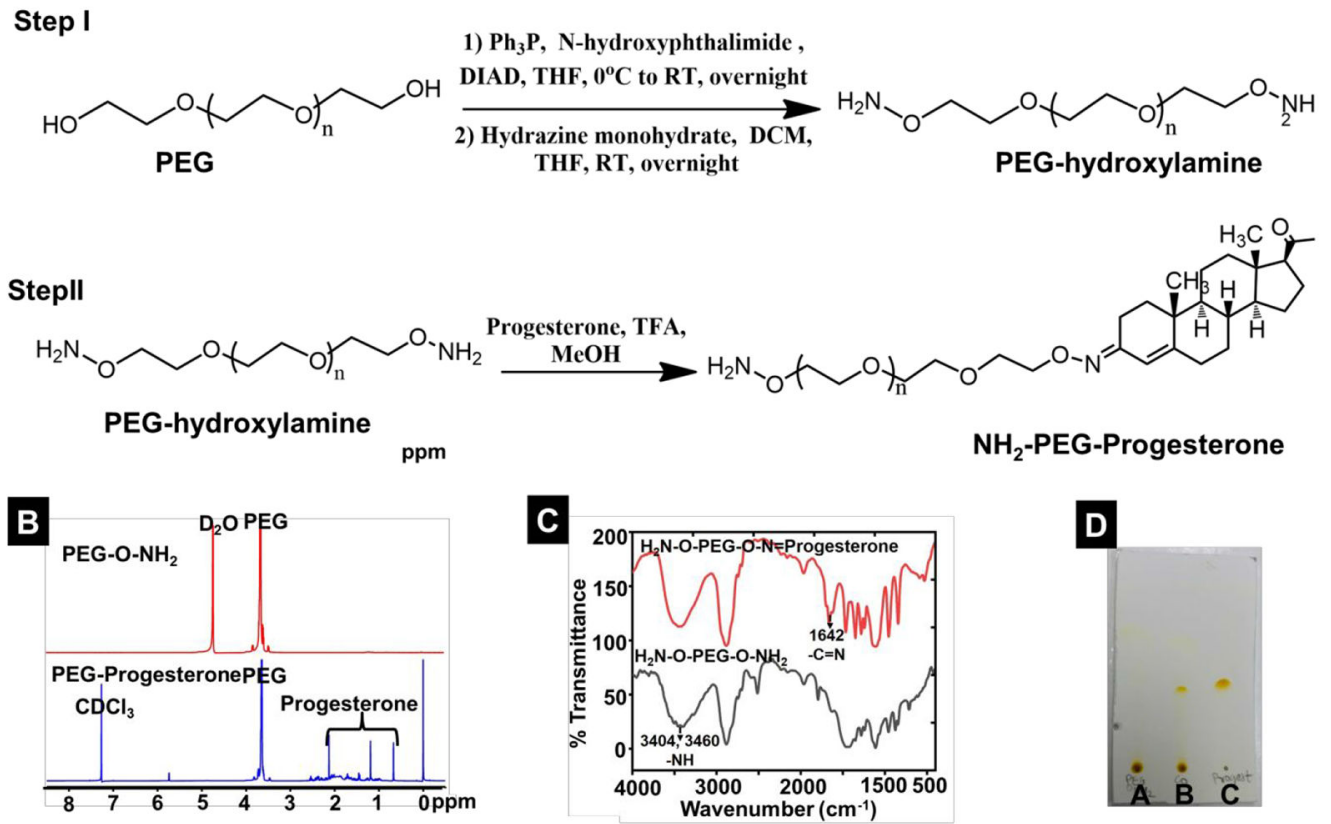

Figure 3.

Synthesis and chemical characterization of $\mathrm{NH}_{2}$-PEG-Progesterone. (A) Synthesis of PEGhydroxylamine. Step I. Conditions: (1) $\mathrm{PPh}_{3}$, N-hydroxypthalimide, DIAD, THF, $0{ }^{\circ} \mathrm{C}$ to room temperature, overnight. (2) Hydrazine monohydrate, THF, reflux, overnight. Step II. Synthesis of $\mathrm{NH}_{2}$-PEG-Progesterone. Conditions: Progesterone, TFA (catalytic), $\mathrm{MeOH}, 40$ ${ }^{\circ} \mathrm{C}$, overnight. (B) ${ }^{1} \mathrm{H}-\mathrm{NMR}$. (C) FTIR, (D) TLC ((A): $\mathrm{NH}_{2}-\mathrm{O}-\mathrm{PEG}-\mathrm{ONH}_{2}$, (B): Co-spot, (C): $\mathrm{NH}_{2}$-PEG-Progesterone). 
Analyte: $\mathrm{NH}_{2}$-PEG-Estrone
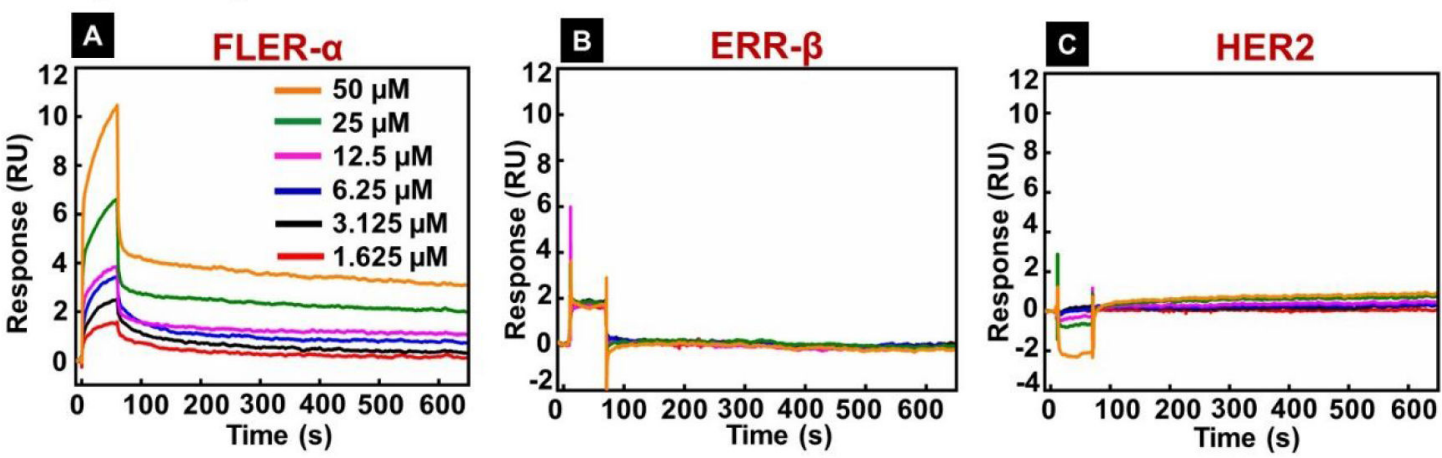

Analyte: $\mathrm{NH}_{2}$-PEG-Progesterone
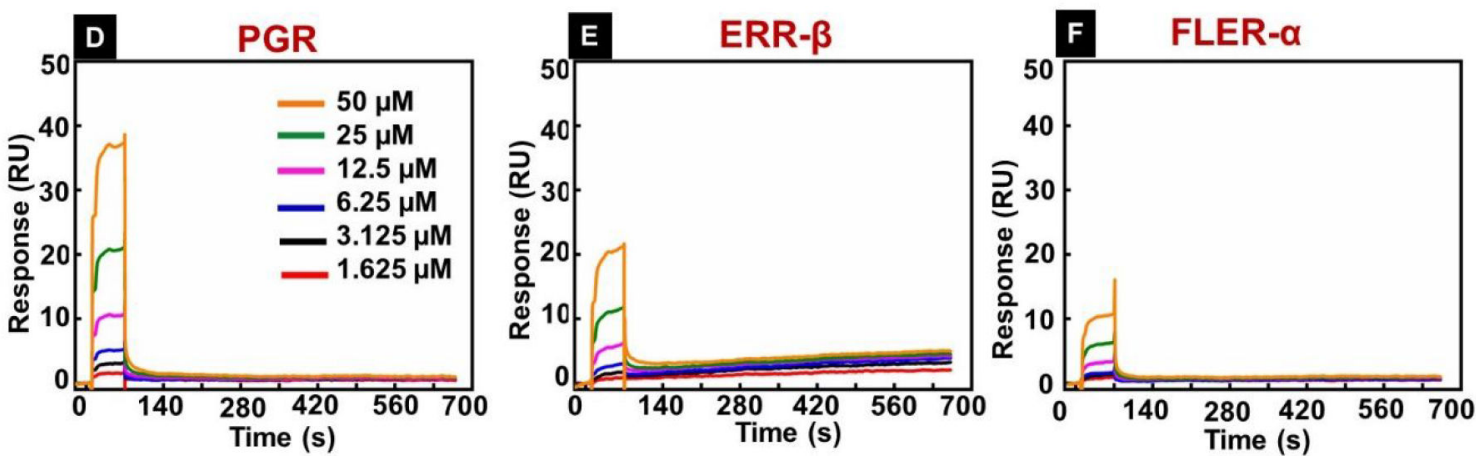

Figure 4.

SPR sensorgrams. Top Panel (A-C), (A) Binding affinity curves of $\mathrm{NH}_{2}$-PEG-Estrone with FLER-a. (B-C) ERR- $\beta$ and HER2 are the negative controls for FLER- $\alpha$. Bottom Panel (DF), (D) Binding affinity curves of $\mathrm{NH}_{2}$-PEG-Progesterone with Progesterone receptor. (E-F) $\mathrm{NH}_{2}$-PEG-Progesterone cross-reacted a little bit with ERR- $\beta$ and FLER- $\alpha$. 

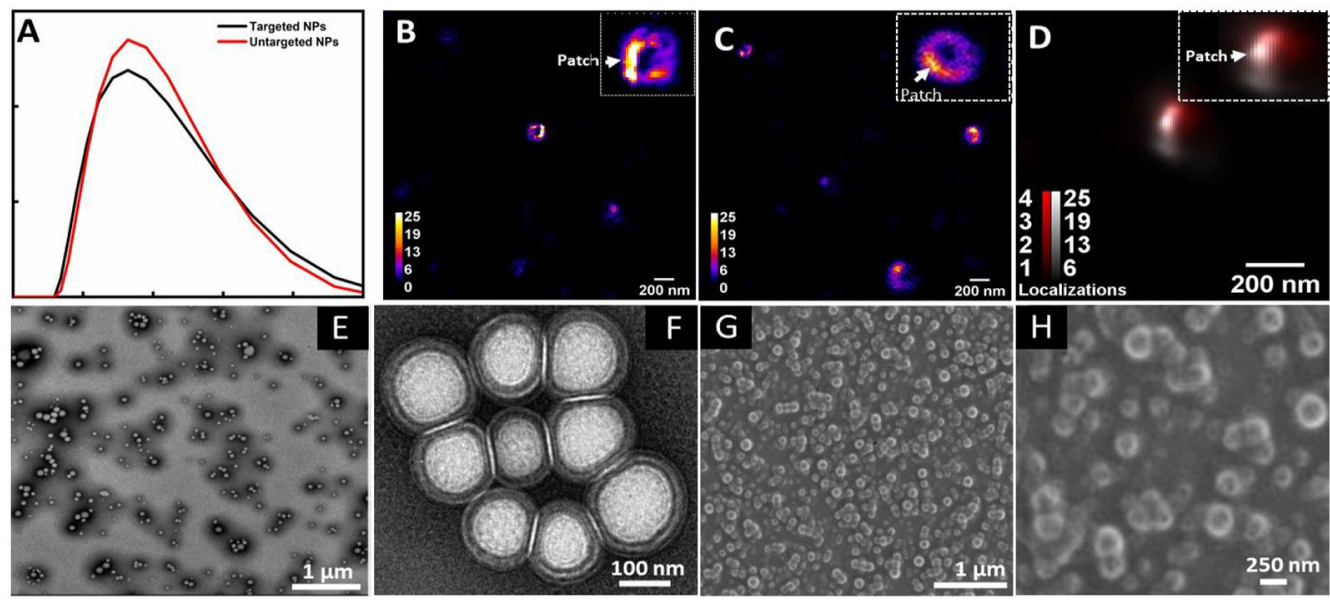

Figure 5.

Physical characterization of MTMPPPCAs. (A) Particle size distribution of MTMPPPCAs and UTMPPPCAs. 2D Stochastic Optical Reconstruction Microscopy (STORM) image of $\mathrm{NP}$ functionalized with $\mathrm{NH}_{2}$-PEG-Estrone-Alexa 647 (B), $\mathrm{NH}_{2}$-PEG-Progesterone-Cy3B (C), $\mathrm{NH}_{2}$-PEG-Estrone-Alexa 647/ $\mathrm{NH}_{2}$-PEG-Progesterone-Cy3B (D). The inset shows the patchy nature of MTMPPPCAs and its hollow core. TEM (E-F) and SEM micrographs (GH) exhibit the MTMPPPCAs' morphology and surface structure, respectively. 

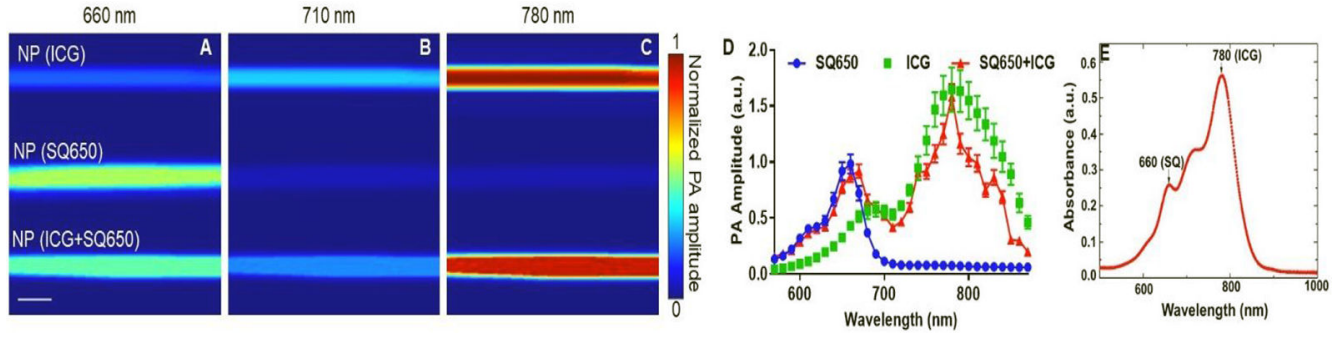

Figure 6. PA spectra of MTMPPPCAs.

(A-C) PACT images of nanoparticles with ICG, nanoparticles with SQ650 and MTMPPPCAs in silicone tubes at wavelengths of 660,710, and $780 \mathrm{~nm}$, respectively. Scale bar, $1 \mathrm{~mm}$. (D) PA spectra of MTMPPPCAs with ICG (green line), nanoparticles with SQ650 (blue line) and the MTMPPPCAs (red line), (E) Absorption spectra of MTMPPPCAs. 


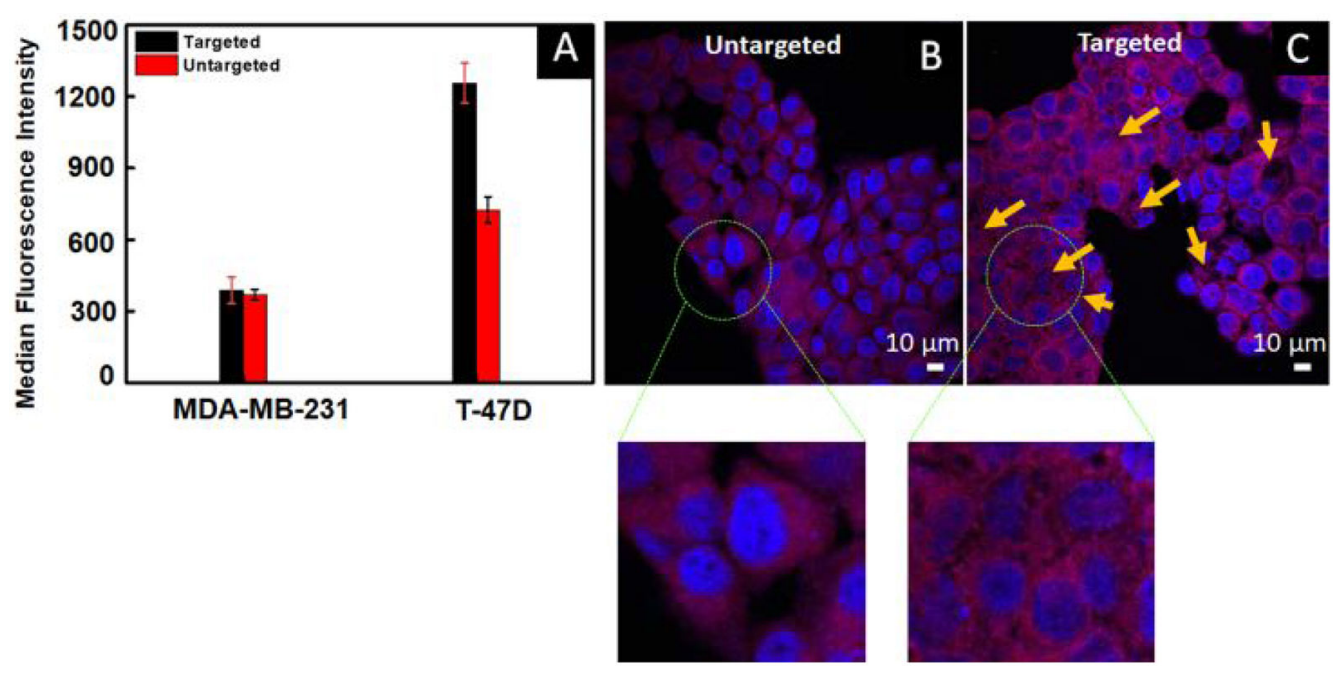

Figure 7.

Cellular uptake studies of MTMPPPCAs and UTMPPPCAs in T-47D and MDA-MB-231 breast cancer cells. (A) The MTMPPPCAs uptake doubled after $24 \mathrm{~h}$ of incubation compared with UTMPPPCAs. Error bar, standard deviation $(n=3)$. (B-C) Confocal microscopy images of MTMPPPCAs cell uptake in T-47D cells after $24 \mathrm{~h}$ incubation with the section insets. The yellow arrows point out the presence of MTMPPPCAs in the cytoplasm or nucleus of the cell. There is a higher cell uptake in the targeted sample compared to the untargeted as shown by the close-up images. 


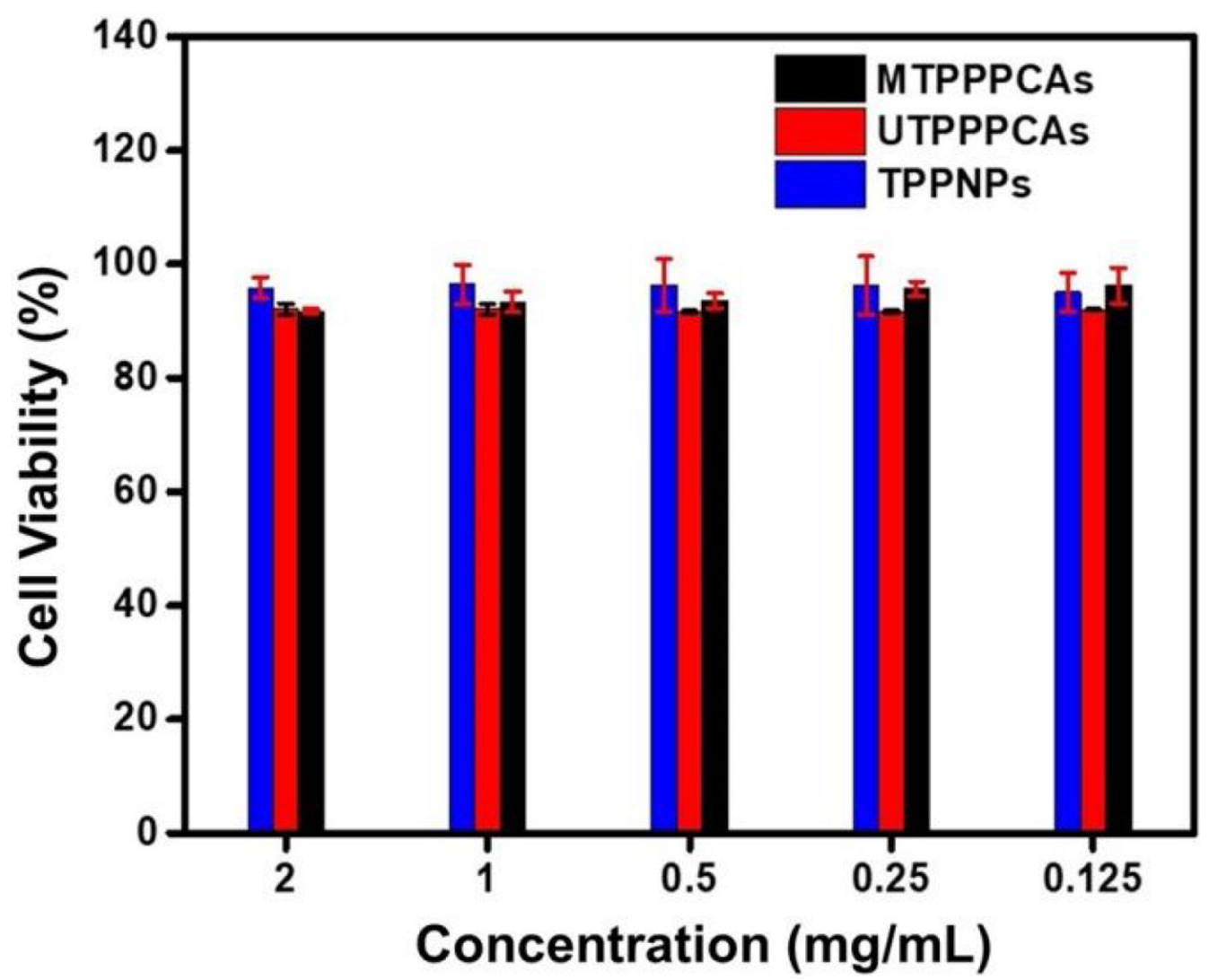

Figure 8.

In vitro evaluation of the cellular toxicity of MTMPPPPCAs. Cell toxicity assessment of T-47D cells in the presence of MTMPPPCAs, UTMPPPCAs and TPPPNPs (control) after $24 \mathrm{~h}$ of incubation at concentrations ranging from $0.125 \mathrm{mg} / \mathrm{mL}$ to $2 \mathrm{mg} / \mathrm{mL}$. Results were presented as percentage cell viability (mean \pm SD) from three independent experiments 


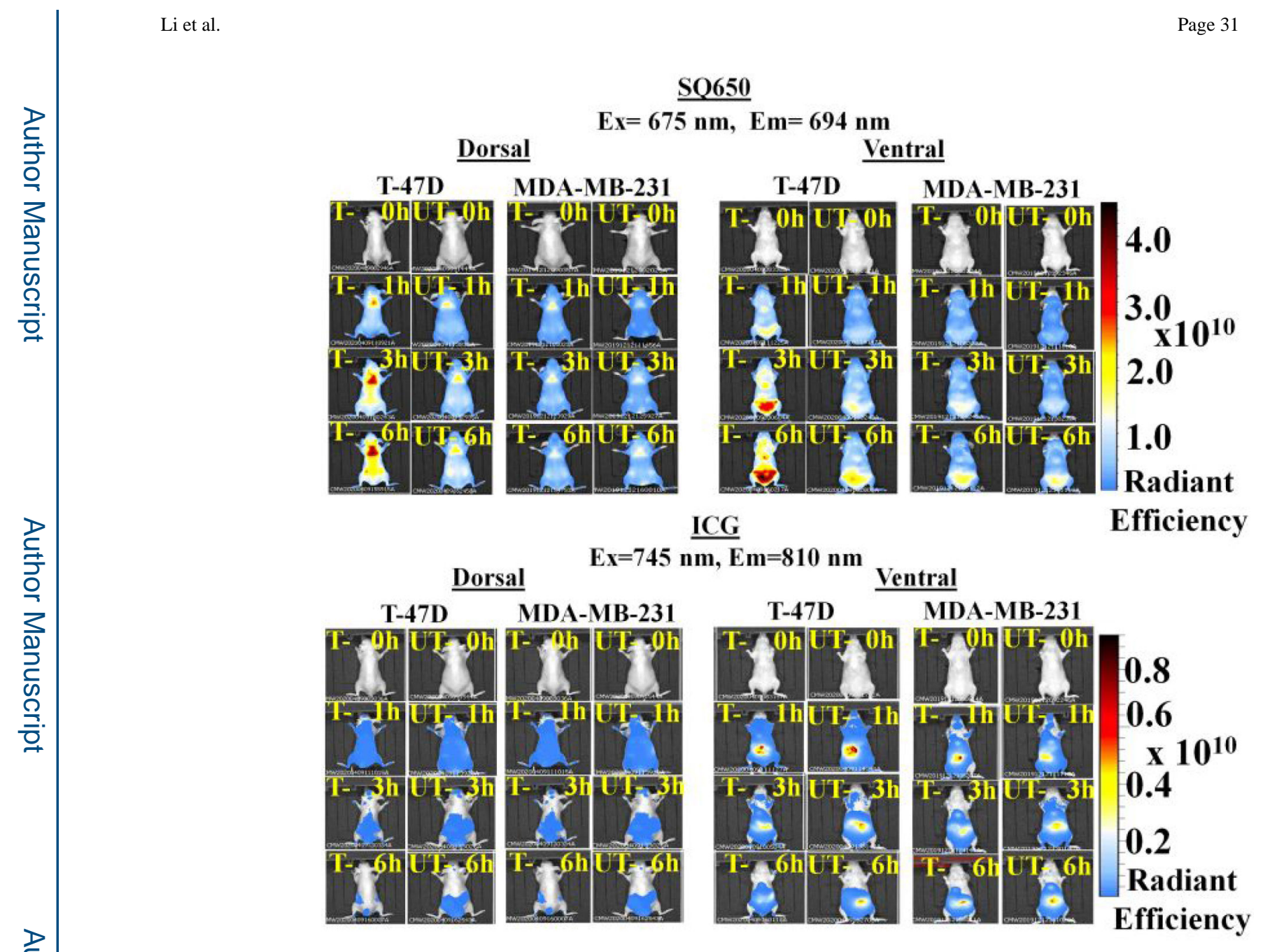

Figure 9.

In vivo biodistribution studies. Mice were administered with a combination dose of MTMPPPCAs (T) and UTMPPPCAs (U) in T47-D tumors and MDA-MB-231 tumors (negative control), and imaged by the IVIS system at 1, 3, 6-h time points. Biodistribution studies using $675 \mathrm{~nm}$ and $694 \mathrm{~nm}$ as the excitation and emission wavelengths, respectively, detected the presence of the SQ650. The images were taken at both dorsal and ventral positions. Biodistribution studies using $745 \mathrm{~nm}$ and $810 \mathrm{~nm}$ as the excitation and emission wavelengths, respectively, detected the presence of the ICG. 


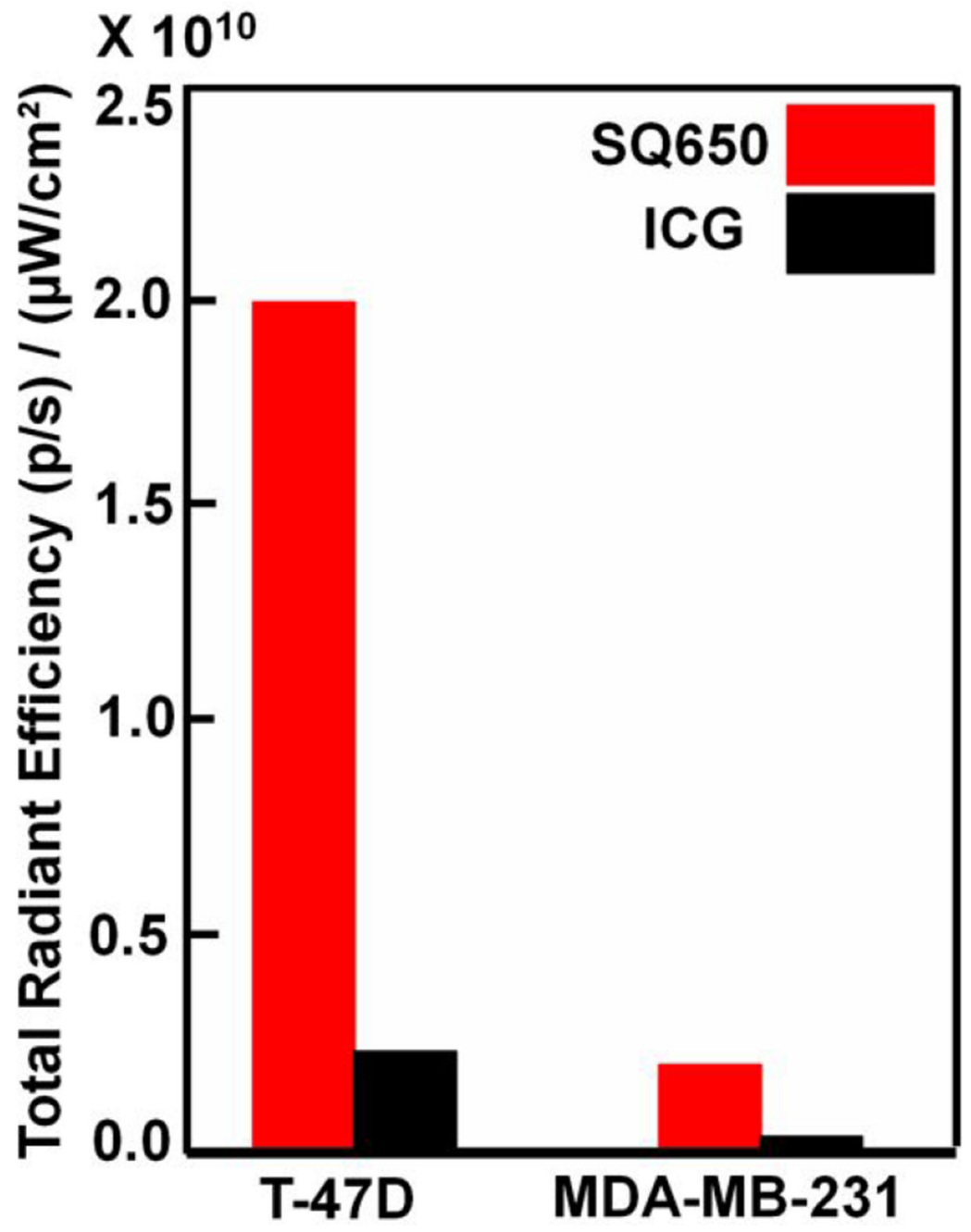

Figure 10.

Ex vivo tumor uptake studies. MTMPPPCAs uptake by T-47D and MDA-MB-231 (negative control) tumors registered with the SQ650 and ICG. 


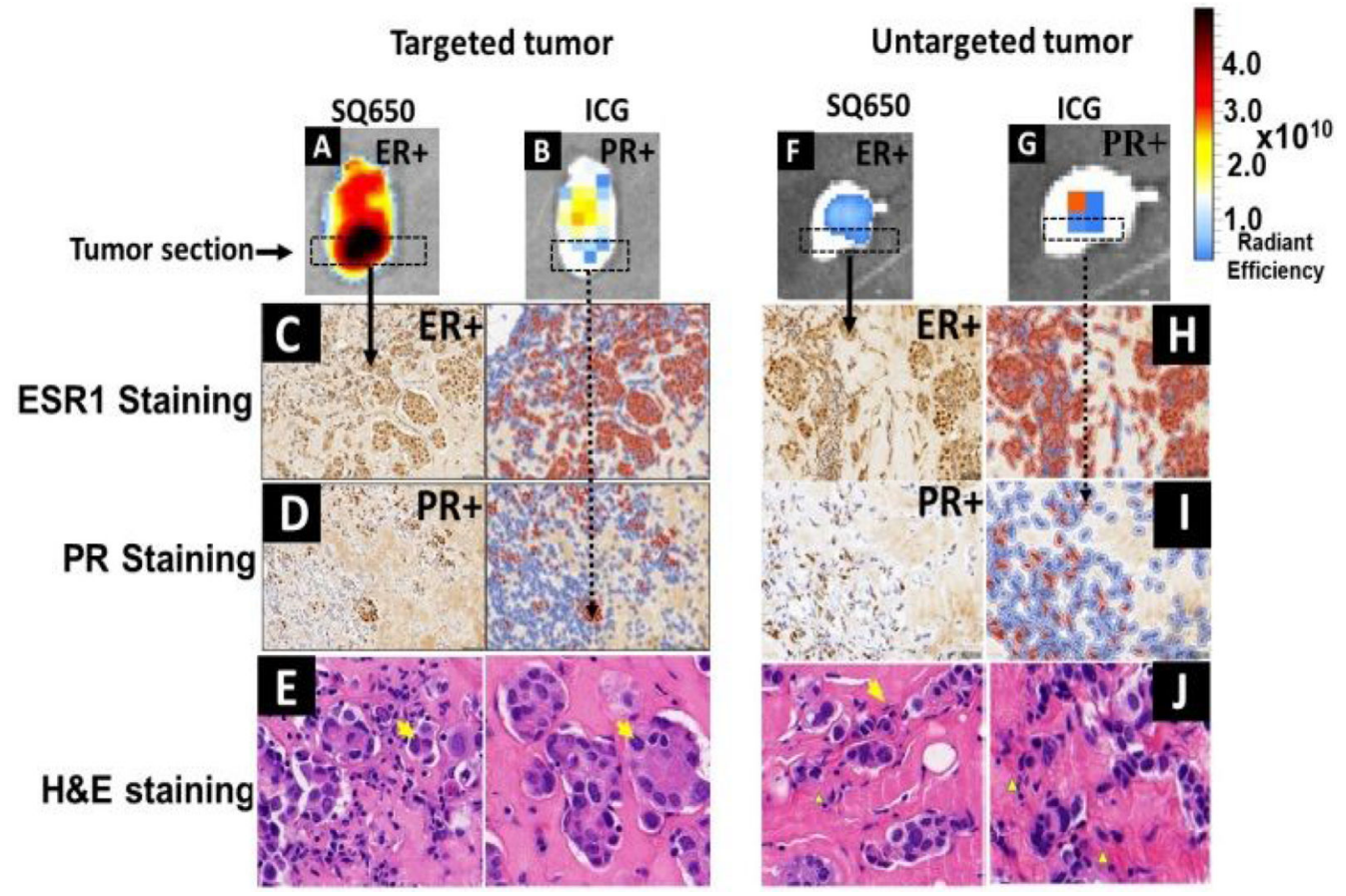

Figure 11.

Visualization of ITH in ex vivo tumors using fluorescence imaging and validating these results with IHC. (A-G) show fluorescence images of targeted (A-B) and untargeted tumors $(\mathrm{F}-\mathrm{G})$ in which ER+ and PR+ were detected with SQ650 and ICG, respectively. More MTMPPPCAs uptake in the targeted tumor were observed than that of the untargeted. IHC studies confirm the presence of ER+ and PR+ in both targeted (C-D) and untargeted tumors (H-I) by staining the tumor breast cancer cell nuclei (brown areas). This figure portrays magnified pictures taken from the tumor sections indicated in (Figure $10 \mathrm{~A}, \mathrm{~B}, \mathrm{~F}, \mathrm{G})$. The tumor sections were formalin-fixed paraffin embedded and immunostained separately with a primary anti-Estrogen receptor 1 (ESR1) and anti-progesterone antibodies (PR). ER+ and $\mathrm{PR}+$ were visualized with 3'3-diaminobensidine (DAB) (brown color). E-J are representative images of hematoxylin and Eosin staining on FFPE showing the nuclei (blue) and cytoskeleton (pink) of the tumor breast cancer cells. The scale bar is $50 \mu \mathrm{m}$. 

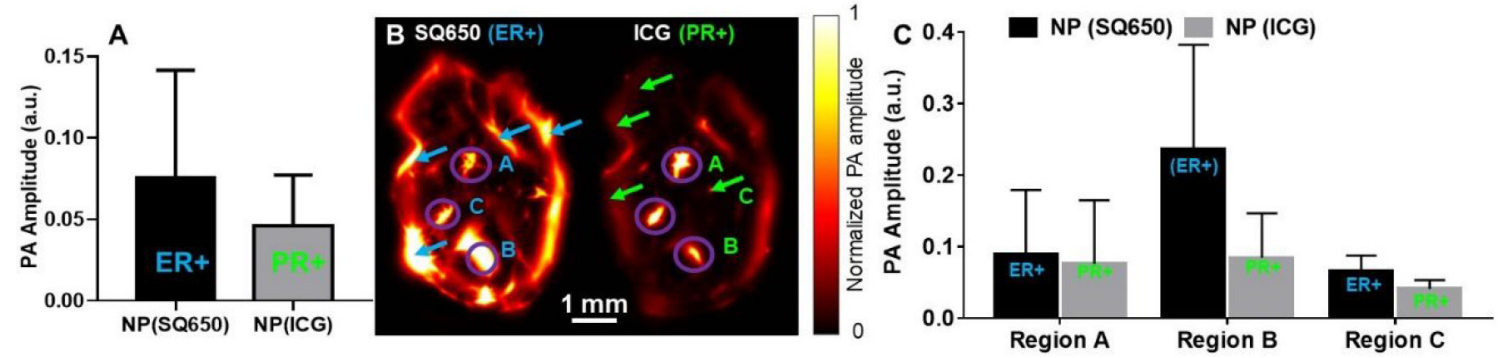

Figure 12.

PA evaluation of MTMPPPCAs in the tumor ex vivo. (A) PA signals from SQ650 and ICG, computed by spectral unmixing. (B) PA images showing the distribution and localization of $\mathrm{ER}+$ and $\mathrm{PR}+$ receptors in the tumor via spectral unmixing. (C) Comparison of ER+ and PR + in PA amplitude in colocalized regions. 


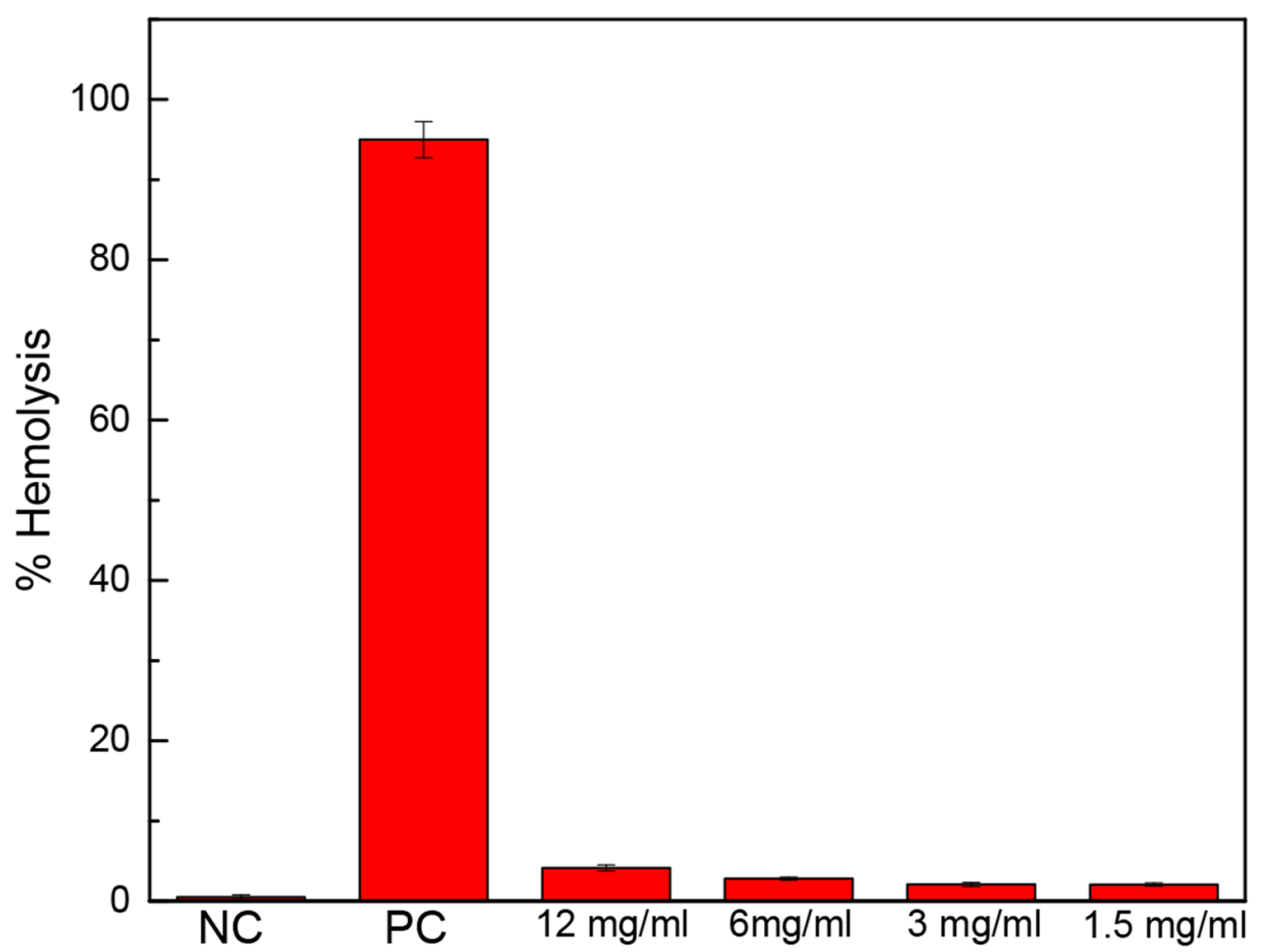

Figure 13.

Hemolysis percent of MTMPPPCAs at different concentration compared with the negative and positive controls. Diluted Total Blood Hemoglobin in $\mathrm{Ca}^{2+} / \mathrm{Mg}^{2+}$ - free PBS and Triton $\mathrm{X}-100(10 \mathrm{mg} / \mathrm{ml})$ are the negative and positive control, respectively. The highest concentration $12 \mathrm{mg} / \mathrm{ml}$ and lowest $1.3 \mathrm{mg} / \mathrm{ml}$ concentrations induced $4.1 \%$ and $2.1 \%$ of hemolysis, correspondingly. Thus, MTMPPPCAs at these concentrations are not compatible with blood. 

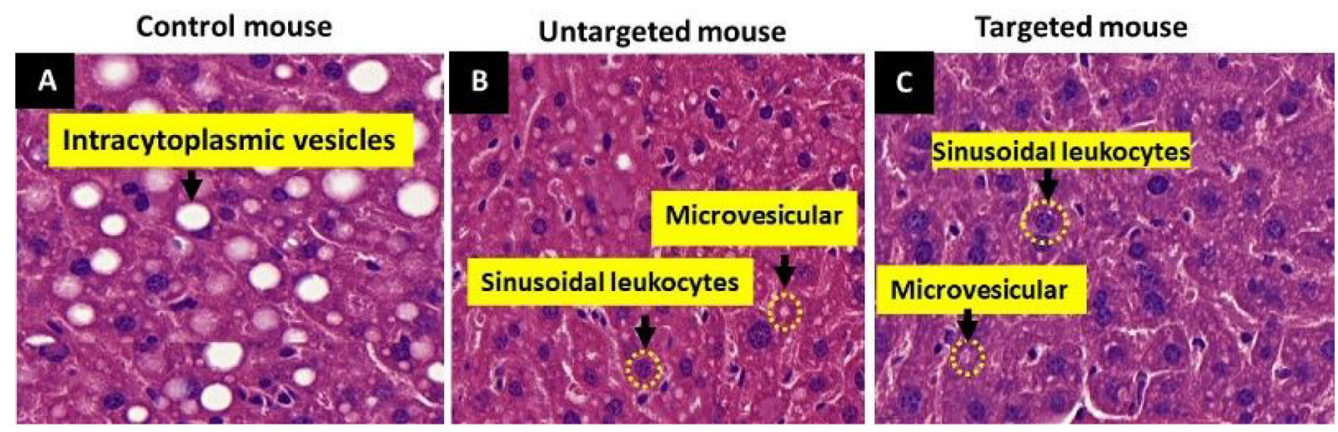

Figure 14. Hepatoxicity studies of MTMPPPCAs.

H\&E liver sections of control mouse (i.e., no MTMPPPCAs administration) (A), untargeted mouse (B), and targeted mouse (C) were subject to pathology analysis. The pathology results show no evidence of liver toxicity caused by MTMPPPCAs because there is an absence of macrophages and necrosis. It should be noted that the control mouse (A) has a significant hepatocellular fatty change (minimal to mild, white circles) shown as intracytoplasmic vesicles. However, this phenomenon was not observed in the untargeted and targeted mice. Thus, the presence of hepacellular fatty change is not due to the MTMPPPCAs but to other factors. The presence of leuokocytes and microvesicular in (B and $\mathrm{C}$ ) is due to immunocompromised nature of the athymic nude mice. 